\title{
,neu \\ Design and Analysis of VTOL Operated Intercity Electrical Vehicle for Urban Air Mobility
}

\author{
Arumugam Akash, Vijayaraj Stephen Joseph Raj, Ramesh Sushmitha, Boga Prateek (1), \\ Sankarasubramanian Aditya (i) and Veloorillom Madhavan Sreehari * (i) \\ School of Mechanical Engineering, SASTRA Deemed University, Thanjavur 613401, India;

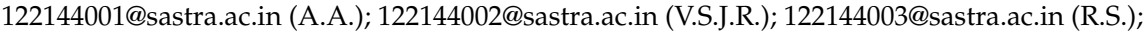

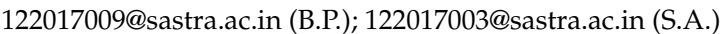 \\ * Correspondence: sreehari_vm@mech.sastra.edu
}

Citation: Akash, A.; Raj, V.S.J.; Sushmitha, R.; Prateek, B.; Aditya, S.; Sreehari, V.M. Design and Analysis of VTOL Operated Intercity Electrical Vehicle for Urban Air Mobility. Electronics 2022, 11, 20. https:// doi.org/10.3390/electronics11010020

Academic Editors: Rafael Casado and Aurelio Bermúdez

Received: 3 November 2021

Accepted: 19 December 2021

Published: 22 December 2021

Publisher's Note: MDPI stays neutral with regard to jurisdictional claims in published maps and institutional affiliations.

Copyright: (C) 2021 by the authors. Licensee MDPI, Basel, Switzerland. This article is an open access article distributed under the terms and conditions of the Creative Commons Attribution (CC BY) license (https:// creativecommons.org/licenses/by/ $4.0 /)$.
Abstract: This paper discusses the conceptual design of an intercity electrical vertical take-off-andlanding aircraft. A literature survey of existing eVTOL aircrafts, configuration selection, initial sizing, weight estimation, modelling and analysis was conducted. The present intercity eVTOL aircraft has the capability to carry four passengers along with one pilot for a distance of $500 \mathrm{~km}$. Two specific aircraft modes, such as air-taxi and air-cargo mode, are considered in the present design. Market entry is predicted before 2031. Subsequently, innovative technologies are incorporated into the design. The present design features an aerodynamically shaped fuselage, tapered wing and a V-tail design. It can carry a nominal payload of $500 \mathrm{~kg}$ to a maximum range of $500 \mathrm{~km}$ at a cruise speed of Mach 0.168 . The present eVTOL is comprised of a $5 \mathrm{~m}$-long fuselage and an $11 \mathrm{~m}$ wingspan. It utilizes six tilt-rotor propeller engines. The maximum take-off weight and empty weight are $1755 \mathrm{~kg}$ and $1255 \mathrm{~kg}$, respectively. The unit price is expected to be between USD 14.83 and 17.36 million. This aircraft has an aesthetically pleasing, intelligent and feasible design.

Keywords: eVTOL; urban air mobility; air taxi

\section{Introduction}

The evolution of the aeronautical industry in the coming decades comes with unique challenges. A new class of aircraft will be needed as there is an increasing demand for intercity air travel. Electrically powered vertical take-off-and-landing aircrafts (eVTOL) are quite essential to avoid delays due to traffic congestion, ensure environmentally friendly operations and operate with the least possible ground support infrastructure. eVTOLs are best suited for intercity air travel since they have reduced noise during operations, fewer maintenance requirements, are more economical, are easily controllable and have feasible autonomy options. The main challenge is providing the assurance of aircraft's safety as the eVTOL is supposed to have a flight profile through residential areas. An aircraft's safety can be improved by an in-depth understanding of the design concept followed by testing. A conceptual design is the first step in designing an eVTOL, followed by a preliminary and detailed design. Thus, a conceptual design of an eVTOL has been proposed in this paper.

The paper is structured as follows: A thorough literature study has been conducted in Section 2. The layout, including configuration selection, is presented in Section 3. The mission profile and design methodology are discussed in Section 4. The wing, fuselage, tail, powerplant, landing gear and control surface sizing are discussed in Sections 5 and 6 . Section 7 contains the constraint and sensitivity analysis. Section 8 presents the CG estimation. Aerodynamic and structural analyses are discussed in Sections 9 and 10. Sections 11 and 12 present performance and stability calculations. Section 13 discusses the cost estimation and technological forecast of batteries and Section 14 discusses the relevance. 


\section{Literature Study}

In the last few years, a steady increase in studies related to eVTOLs has been observed. However, the majority of the designs have to be iterated to futuristic technologies and relevant to intercity transportation. Kraenzler et al. [1] studied the conceptual design of an eVTOL for urban mobility transport. They discussed three possible concepts for eVTOL such as multicopter, lift and cruise and tilt-wing. They concluded that the tilt-wing configuration is highly efficient for long-range missions in comparison to lift and cruise and multirotor concepts. Jianqiao et al. [2] investigated an eVTOL for intercity transportation. They focused on having a range less than 200 miles, 10 passengers and $1000 \mathrm{~kg}$ payload. This study yielded a high-level depiction of the trade-off between the range and payload. They concluded that they need to increase the motor specifications and battery sizing to suit the payloads and mission requirements even though it affects the cost of the mission. The Mistral air taxi is a four-seater eVTOL aircraft designed by a team named 'The Huggy's Birds' for the AIAA competition [3]. This report provides basic insights into the design methodology and analysis process for an eVTOL aircraft. The report discusses how to design different components of aircrafts and analyse their performance.

Razvan and Blaj [4] examined the design of a tilt-wing UAV for emergency missions. The paper highlights the advantages of using a tilt-wing over other VTOL configurations. The tilt-wing offers more lifting power in hover as the slipstream hits the wing on its smallest dimension. Alessandro and Enrico [5] conducted research on the comparison of different eVTOL configurations based on five main parameters: disk loading, total hover time, cruise speed, range and flight time. Lift and cruise and tilt-wing configurations have a higher range and cruise speed compared to multirotor configurations. Multirotor configurations have a better hover time than all of the other configurations. They have concluded that the chosen configuration depends mainly upon the mission profile. Charles et al. [6] described that the tilt-wing has many advantages compared to other configurations such as higher cruise speed, range, altitude capability, fewer vibrations and high comfort.

Anubhav Datta [7], from the University of Maryland in 2018, investigated the technology status of an eVTOL aircraft. He provided information about various parameters involved to design an eVTOL based on their performances. Lithium-based batteries are mostly used in eVTOL aircrafts since it has high specific energy, longer lifetime and their prices remain fair in comparison with other types of batteries. He also explored the utilization of hydrogen fuel cells as a renewable and clean energy source. Hydrogen gas can save four to five times of energy in comparison to current batteries; however, high-powered fuel stacks are heavy. Ajoy Kumar Kundu [8] also described the sizing of an electrical battery-powered aircraft. It included formulae for finding the range of an electric aircraft using battery energy density. Saeed Farokhi [9] states that lithium-ion batteries have higher voltage, higher power quality and quicker rechargeability than other existing batteries. Therefore, most electric aircrafts use these batteries for various purposes.

Apart from these, some other eVTOL design patents were studied. Ira F. Kuhn Jr patented [10] a hybrid eVTOL tilt-rotor aircraft that was designed to accomplish a hoverout-of-ground effect. The aircraft can achieve a hover-out-of-ground effect for four minutes while using the power of at least one electric motor and carrying at least 1000 pounds. The electric energy store (battery, fuel cells, etc.) can be configured to deliver up to $400 \mathrm{Wh} / \mathrm{kg}$ of specific energy density. He also stated that the electric motors can carry a fail-over operation where a first motor can assist a second motor's rotor while the second motor is out of service. This is called one propulsion motor inoperative.

Roger N. Pham [11] patented a high-performance VTOL in which he claimed the advantages of a tilt-rotor VTOL when compared to other conventional fixed-wing aircraft and helicopters. He stated that the tilt-rotor VTOL is much safer, more economical, has a higher speed and range in comparison to an aircraft. Tilt-rotor VTOLs can be used to expand the vast number of frequent fliers in general aviation and can decrease the inconveniences of commercial air travel, traffic congestion and significant delays. The high speed and high manoeuvrability of the tilt-rotor VTOL can be used for military applications 
and other missions such as coast guard, border patrol, drug interdiction duties as well as search and rescue.

Akshat et al. [12] proposed a baseline procedure of the conceptual design of an eVTOL aircraft for urban air mobility. They highlighted the importance of the disk loading parameter as it is used to estimate the hover lift efficiency. eVTOLs having larger disc areas contribute to higher hover efficiency, whereas smaller tilt-rotor system eVTOLs provide more speed and less hover efficiency. Alessandro and Enrico [13] highlighted the key aspects which need to be considered while performing the conceptual design of an eVTOL. They pointed out the factors that affect the range of an eVTOL, which include lift-to-drag ratio, propulsive efficiency, battery energy density and battery-mass-to-total-mass ratio. They also concluded that the disk actuator area is directly proportional to the total mass, directly proportional to the cube of the thrust-to-weight ratio and inversely proportional to the square of the battery specific power and to the square of the battery-mass-to-totalmass ratio.

Giuseppe et al. [14] presented a new conceptual design methodology for the tilt-wing type eVTOL known as 'TiltOne'. Two tilt-wing configurations, known as "single mission" and "multi mission", were considered. A single-mission approach would reduce noise and ease manufacturability and ground operations, whereas a multiple-mission approach would boost the operational and technical capabilities of the eVTOL. Bacchini et al. [15] studied the impact of the lift propeller drag on the performance of the lift and cruise eVTOL aircraft. They concluded that by retracting the lift propellers inside the fuselage, there was a $13 \%$ increase in range, $21 \%$ increase in flight speed and $38 \%$ reduction in drag.

\section{Study of Similar Aircrafts}

Every machine in the world can be improved further and, in order to do so, a primary understanding of it is necessary. Hence, in order to understand the current scenario of the VTOL and eVTOL industry, various existing models of eVTOLs were studied and all basic key parameters were discussed for designing the present eVTOL. By considering the requirements of an intercity eVTOL aircraft, it was narrowed down to the tilt-rotor type eVTOLs shown in Table 1. Table 1 lists the specifications of various parameters such as cruise speed, maximum speed, range, payload weight, powerplant type, number of crew members and the propulsion configuration of various existing eVTOLs with the assumed intercity mission requirements [16].

Table 1. A list of similar and relevant eVTOLs identified.

\begin{tabular}{|c|c|c|c|c|c|c|c|}
\hline Aircraft & $\begin{array}{l}\text { Cruise } \\
\text { Speed } \\
(\mathbf{k m} / \mathbf{h})\end{array}$ & $\begin{array}{c}\text { Maximum } \\
\text { Speed } \\
(\mathrm{km} / \mathrm{h})\end{array}$ & $\begin{array}{l}\text { Range } \\
(\mathbf{k m})\end{array}$ & $\begin{array}{c}\text { Payload } \\
\text { Weight } \\
(\mathrm{kg})\end{array}$ & Power Plant & Crew & Propulsion \\
\hline Vimana AAV & 244 & 280 & 900 & 400 & 200 KW Batteries & 4 & \multirow{5}{*}{$\begin{array}{c}8 \text { propellers } \\
4 \text { propellers for VTOL } \\
\text { and all } 8 \text { propellers } \\
\text { for cruise } \\
6 \text { propellers } \\
4 \text { propellers } \\
4 \text { propellers for VTOL } \\
\text { and all } 8 \text { propellers } \\
\text { for cruise }\end{array}$} \\
\hline $\begin{array}{c}\text { Vertical } \\
\text { AerospaceVA-X4 }\end{array}$ & - & 241 & 161 & 450 & Batteries & $4+1$ & \\
\hline Rolls Royce & - & 402 & 804 & - & 500 KW Batteries & 5 & \\
\hline Overair Butterfly & 240 & 322 & 161 & - & Batteries & $4+1$ & \\
\hline Hyundai S-A1 & 290 & - & 97 & - & $\begin{array}{l}7 \text { high density } \\
\text { batteries }\end{array}$ & $4+1$ & \\
\hline Required & 200 & 250 & 500 & 500 & Green & $4+1$ & \\
\hline
\end{tabular}

\section{Layout}

\subsection{Initial Design and Discussion}

Upon numerous conceptual iterations and analysing multiple design models in OpenVSP software (Open-source software developed by NASA, Washington, DC, USA) [17], the present design was finalized. 


\subsection{Overview of the Present Design}

The present design is a tilt-rotor electric VTOL aircraft with a tapered fixed wing. Six main tilt-rotors are mounted-four on wings and two at the end of the V-tail with the ability to take-off, hover and thrust during cruise and landing. The fuselage is an aerodynamic design inspired from an existing design. The empennage section consists of a V-tail configuration. The landing gear is a retractable tricycle type configuration.

\subsection{Configuration Selection}

Four major VTOL configurations surfaced in the literature survey: multirotor, lift and cruise, tilt-wing and tilt-rotor. Based on the comparative study conducted initially, it was narrowed down to tilt-wing or tilt-rotor as they are appropriate for the range of $500 \mathrm{~km}$ [1]. A tilt-rotor configuration consists of a wing which is very stable and efficient in cruise but causes drag during take-off and landing. Tilt-wing, on the other hand, is very efficient in take-off, hovering and landing [4]. Furthermore, tilt-wing configuration requires actuators to be placed inside the fuselage at the root of the wing. This creates high stress on the fuselage and, hence, a fixed wing with tilt-rotors was chosen.

\subsection{Wing Planform}

There are many types of wing planforms, viz., elliptical, rectangular, sweptback, tapered, etc. Tapered wings are used to decrease the formation of wingtip vortices and, hence, decrease the drag and downwash. However, a higher taper adversely affects the structural integrity of the wing at the tip. Hence, a nominal taper ratio of 0.35 was chosen.

\subsection{Fuselage}

The fuselage is one of the most wetted surfaces of any aircraft. Hence, it becomes of utmost importance to have an aerodynamically efficient fuselage. The present fuselage design was inspired by Bartini Flying Car $[18,19]$. The fuselage will also incorporate the mechanism to switch from air-taxi to air-cargo mode and vice versa according to the mission requirements.

\subsection{Landing Gear}

A major section of the mission profile is cruise. Hence, having non-retractable landing gear will contribute to the drag drastically. Tail dragger landing gear requires the aircraft to be kept at an incident angle; hence, retractable tricycle landing gear was chosen to ensure maximum comfort to the passengers when at rest [20]. The landing gear after retraction will be stored in the belly of the aircraft.

\subsection{Aerodynamic Control Surfaces}

Ailerons - the upward movement of the right aileron produces a decreased lift on the right wing. Conversely, the downward deflection of the left aileron produces growth in lift on the left wing. This differential lift results in an eVTOL aircraft rolling to the right. The same applies for rolling to the left, but the wing deflection is vice versa to the former case [21].

A Ruddervator-A V-Tail design has two slanted tail surfaces unlike a conventional empennage. The two attached tail surfaces perform as both horizontal and vertical stabilisers and each has a ruddervator. The ruddervators have the capability of performing both as a rudder and an elevator. For the elevator, when the stick is pulled back, both 'ruddervators' deflect upwards much like a conventional elevator. When pushing the stick forward, the ruddervators both deflect downwards to result in a pitch-down movement. When the ruddervators move in opposite directions, the result is pure yaw. Motions in between these two create a combination of pitch and yaw effects. Since the pitch and yaw controls are not dependent on each other, a mechanical device called a "mixer" combines their inputs into a proper action for the ruddervator [22]. 
Figure 1 shows a three-dimensional V-tail modelled in OpenVSP with NACA 0010 as the airfoil [23]. The parameter selection and weight estimation were performed. The reason for opting for V-tail configuration over conventional horizontal tail was that it can perform actions of both the horizontal and vertical stabilizers. By combining the two into one component, the wetted surface area decreases, which means the weight decreases and the drag eventually decreases. This decrease in drag increases the cruise speed of the eVTOL aircraft. The other reason was that the average chord length is longer for V-tail than for a conventional tail, which results in less friction drag. Conventional tails have three surface-fuselage joints while V-tail has only two, so interference drag as well as structural stress is minimum. Furthermore, the placement of propellers over the V-tail avoids the downwash of the front Furthermore. The overall control power needed for a combined elevator-rudder input is less than compared to a conventional tail, since a high deflection can be obtained for a small elevator-rudder control input in the V-tail configuration [24].

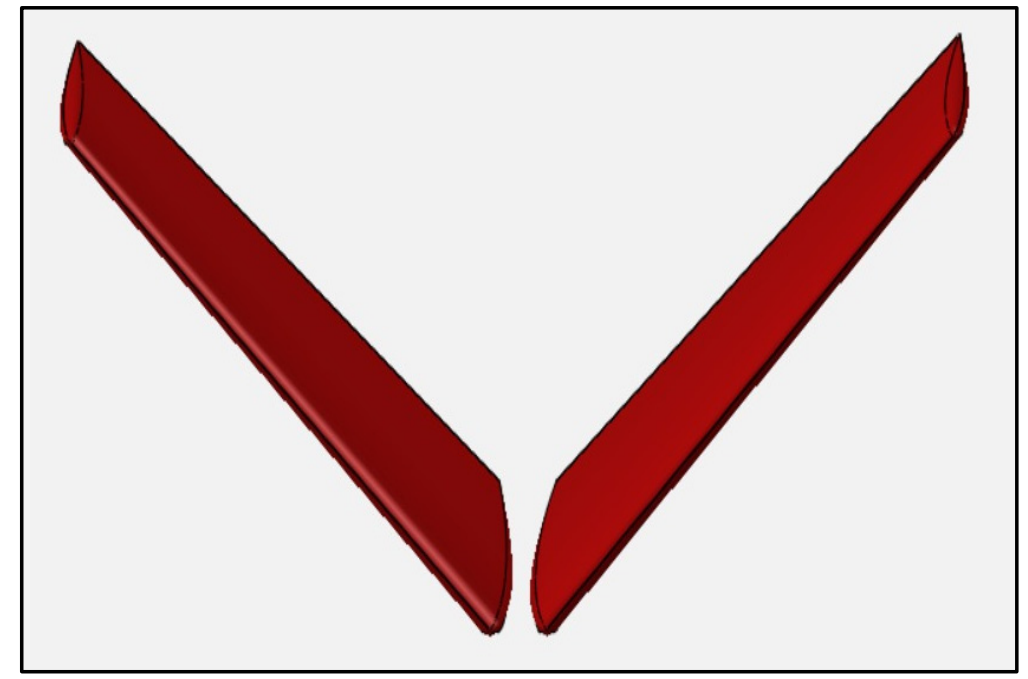

Figure 1. V-tail 3D model (modelled in OpenVSP with NACA 0010 as the airfoil).

\subsection{Propulsion}

The tilt-rotors are mounted to a nacelle which is placed at the leading edge of the wings and the nacelles or shafts can be rotated according to the needs of the eVTOL. The tilt-rotor design has the vertical take-off and landing ability of a helicopter and the speed and range of a fixed-wing aircraft. For vertical flight, the plane of rotation of the rotors is angled to a horizontal position. As the aircraft attains speed, the rotors are tilted forward, with the plane of rotation eventually becoming vertical. In this mode, the rotors deliver thrust and the wing provides lift via the forward motion of the entire aircraft [25].

Open propellers are chosen over the ducted fans for the following reasons:

1. Since the number of propellers in our design is six (four mounted on the wing and two on V-tail), the required thrust is obtained by increasing the diameter of the blades of the propellers. If we opt for larger diameter blades, we have to increase the area of the duct. This increases the wetted surface area which in turn increases the drag. Furthermore, the interaction of duct vortices might reduce the efficiency of the rear propellers. The construction of the duct and its support structure increases manufacturing costs and also increases the total gross weight of the eVTOL aircraft.

2. In a ducted fan, the manufacturing tolerances are essential; the tighter it is, the more efficient the fan is. However, as it becomes tighter, the fans are susceptible to hitting the duct due to the flexing of blades. The pitch control and RPM control become difficult to implement due to the ducts. 
3. In the event of a crosswind on a ducted fan, it results in a sudden pitching moment due to the lip of the duct and the asymmetric inflow to the rotor makes the aircraft lose control and stability [26].

The three-view design of the present eVTOL aircraft which was modelled in OpenVSP is shown in Figure 2. Figure 3 shows an isometric view of the present eVTOL design.

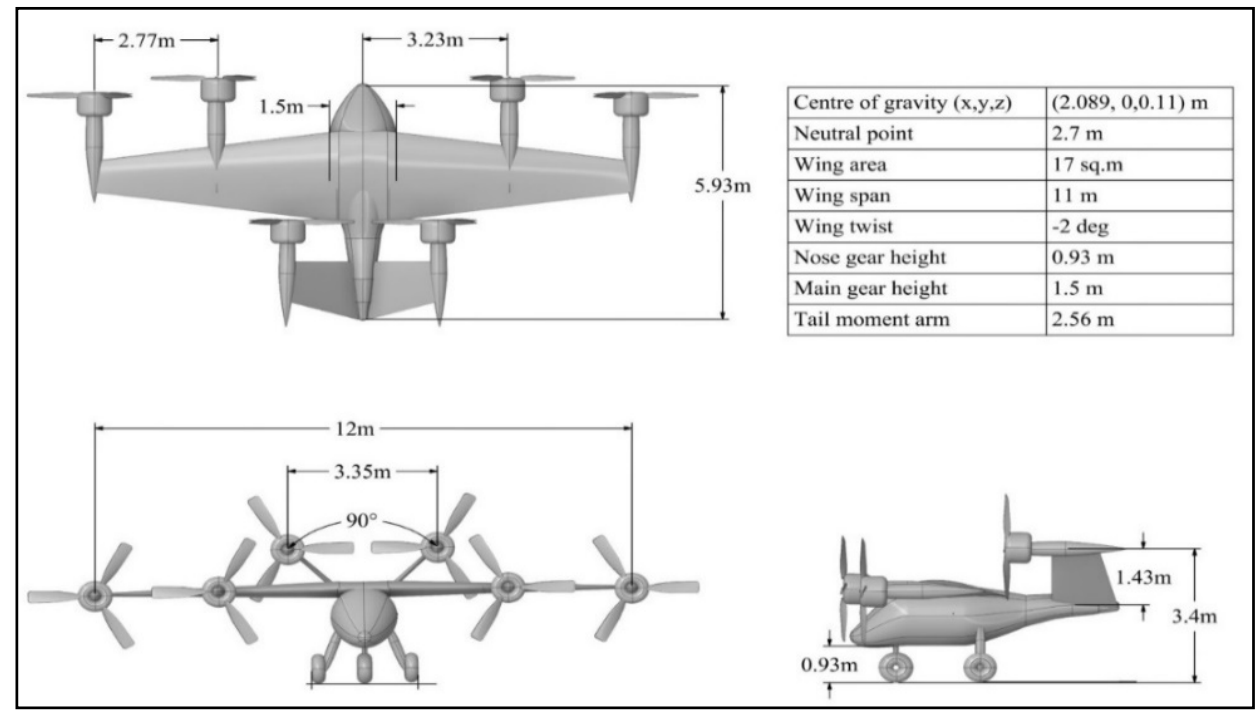

Figure 2. Three-view design of the present eVTOL aircraft.

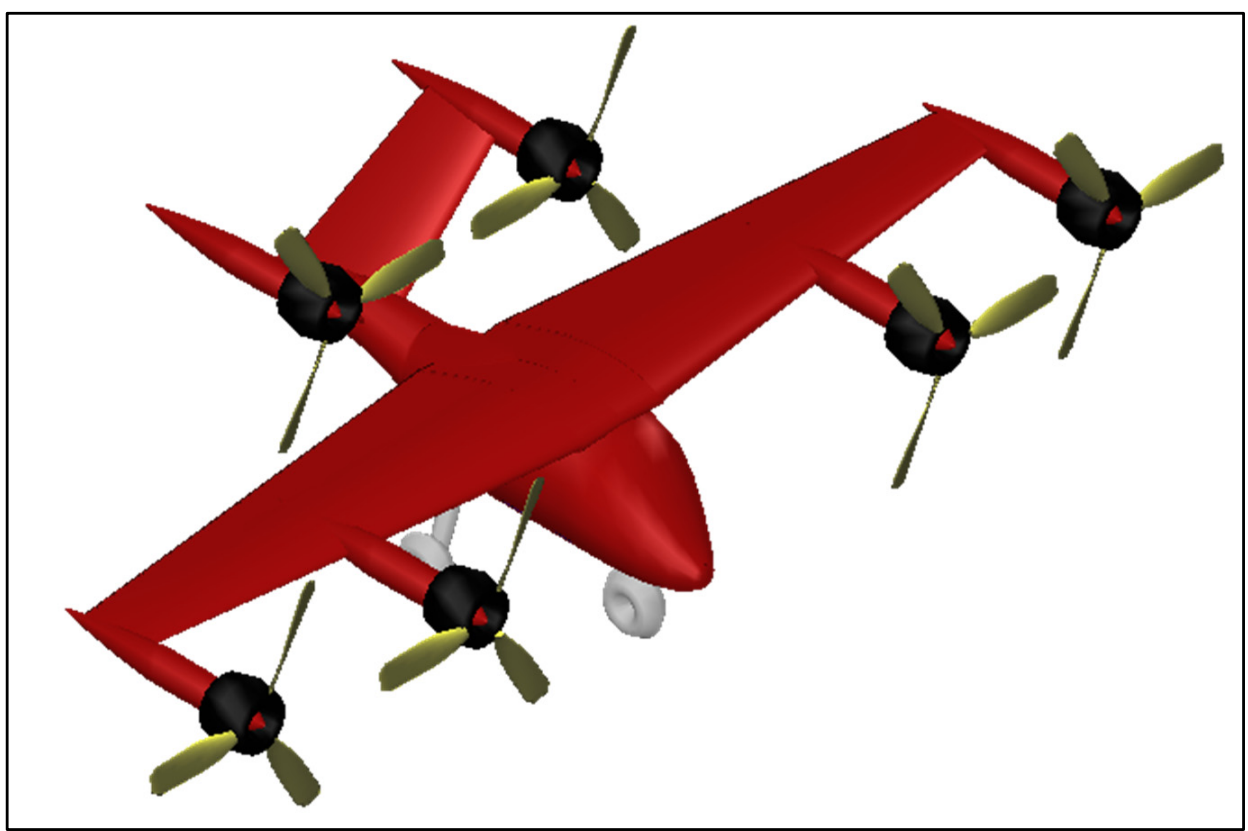

Figure 3. Isometric view of present eVTOL aircraft.

\section{Mission Profile and Preliminary Sizing Calculations}

The objective is to design an eVTOL aircraft considering intercity transportation. The following mission requirements are considered for intercity travel:

1. Range: 500 km;

2. Crew: one pilot (90 kg with baggage);

3. Payload capacity: $500 \mathrm{~kg}$;

4. Air-taxi mode: Four (04) Passenger and $0.5 \mathrm{~m}^{3}$ cargo hold; 
5. Air-cargo mode: $1.5 \mathrm{~m}^{3}$ cargo hold by removing passenger seats;

6. Cruise and maximum speed: 200 and $250 \mathrm{~km} / \mathrm{h}$ TAS;

7. Powerplant: green propulsion using non-fossil fuel;

8. Operational constraint: take-off and land from building rooftop;

9. Enroute constraint: maintain separation of $>600 \mathrm{~m}$;

10. Entry to market: before 1 January 2031.

The building rooftop helipad dimensions are taken, as quoted in the FAA in the Transport Heliports section [27]. As per the FAA, "The TLOF should be a square or rectangular surface whose minimum length and width should be 1.0 times the rotor diameter $(R D)$ of the design helicopter but not less than 50 feet $(15.2 \mathrm{~m})^{\prime \prime}$.

\subsection{Mission Profile Planning}

The mission profile of the present aircraft can be best described in Figure 4 . The minimum height of the building to take-off was assumed to be $60 \mathrm{~m}$, so a climb distance of $80 \mathrm{~m}$ will clear all medium-sized buildings. For tall buildings, a flight profile can be decided depending on each situation. At $2 \mathrm{~km}$, pressurization is not required, hence why it was chosen.

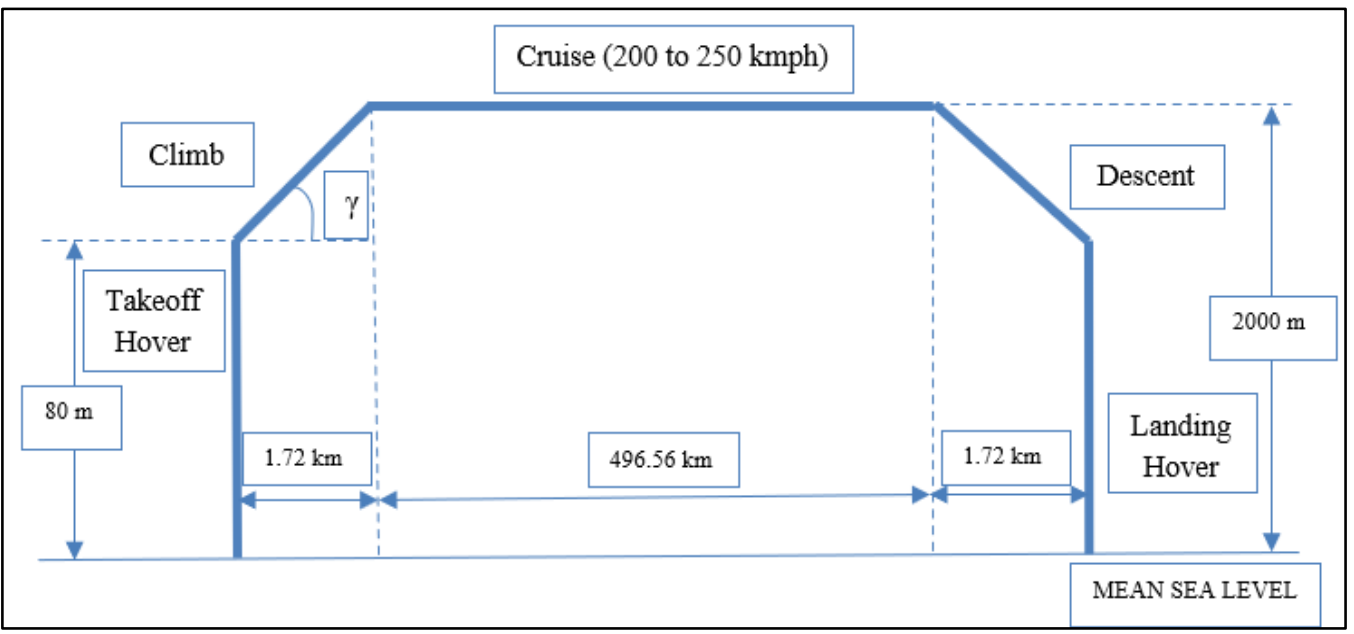

Figure 4. Mission profile.

There are seven phases in the mission profile of the present eVTOL aircraft. The altitude climbed, the distance covered and the velocity required in each phase of the mission profile are tabulated in Table 2.

Table 2. Mission phase parameters.

\begin{tabular}{|c|c|c|c|c|}
\hline Mission Phase & Altitude & Horizontal Velocity & Vertical Velocity & Distance \\
\hline Hover climb & mean sea level to $80 \mathrm{~m}$ & - & $2 \mathrm{~m} / \mathrm{s}$ & - \\
\hline Transition and climb & $80 \mathrm{~m}$ to $400 \mathrm{~m}$ & $1.2 \mathrm{v}_{\text {stall }}$ & $2 \mathrm{~m} / \mathrm{s}$ to $1.2 \mathrm{v}_{\text {stall }}$ & 0 to $120 \mathrm{~m}$ \\
\hline Accelerated $\operatorname{climb}\left(\gamma=14^{\circ}\right)$ & $400 \mathrm{~m}$ to $2000 \mathrm{~m}$ & $1.2 \mathrm{v}_{\text {stall }}$ to $56 \mathrm{~m} / \mathrm{s}$ & $8 \mathrm{~m} / \mathrm{s}$ & $120 \mathrm{~m}$ to $1720 \mathrm{~m}$ \\
\hline Cruise & $2000 \mathrm{~m}$ & 56 to $69 \mathrm{~m} / \mathrm{s}$ & - & $1720 \mathrm{~m}$ to $498.2 \mathrm{~km}$ \\
\hline Decelerated descent & $2000 \mathrm{~m}$ to $400 \mathrm{~m}$ & $56 \mathrm{~m} / \mathrm{s}$ to $1.2 \mathrm{v}_{\text {stall }}$ & $2 \mathrm{~m} / \mathrm{s}$ & $498.2 \mathrm{~km}$ to $499.9 \mathrm{~km}$ \\
\hline Transition and descent & $400 \mathrm{~m}$ to $80 \mathrm{~m}$ & $1.2 \mathrm{v}_{\text {stall }}$ & $2 \mathrm{~m} / \mathrm{s}$ & $499.9 \mathrm{~km}$ to $500 \mathrm{~km}$ \\
\hline Hover descent & $80 \mathrm{~m}$ to mean sea level & - & $1 \mathrm{~m} / \mathrm{s}$ & - \\
\hline
\end{tabular}

\subsection{Initial Sizing, Methodology and Payload-Range Diagram}

To understand various sizing methodologies, several pieces of literature were studied [28]. Upon which, the methodology was decided and the initial sizing of the subsystems was calculated. Table 3 shows the weight estimation of various subsystems. 
Table 3. Weight split up.

\begin{tabular}{cc}
\hline Components & Weight (kg) \\
\hline Fuselage & 240 \\
Wing & 160 \\
V-Tail & 26 \\
Landing gear & 50 \\
Battery & 513 \\
Payload & 500 \\
Motors & 120 \\
Flight Controls & 26 \\
Rotors & 20 \\
Pilot/crew & 90 \\
Other empty weight & 10 \\
\hline Total & 1755 \\
\hline
\end{tabular}

\subsubsection{Methodology for Sizing}

The iteration methodology involved in the sizing process of the present eVTOL aircraft is shown in Figure 5. The iteration process was carried out in the estimation of weights/sizing of the wing, fuselage, horizontal tail, flight controls and landing gear. Equations (1)-(6) were taken from [28].

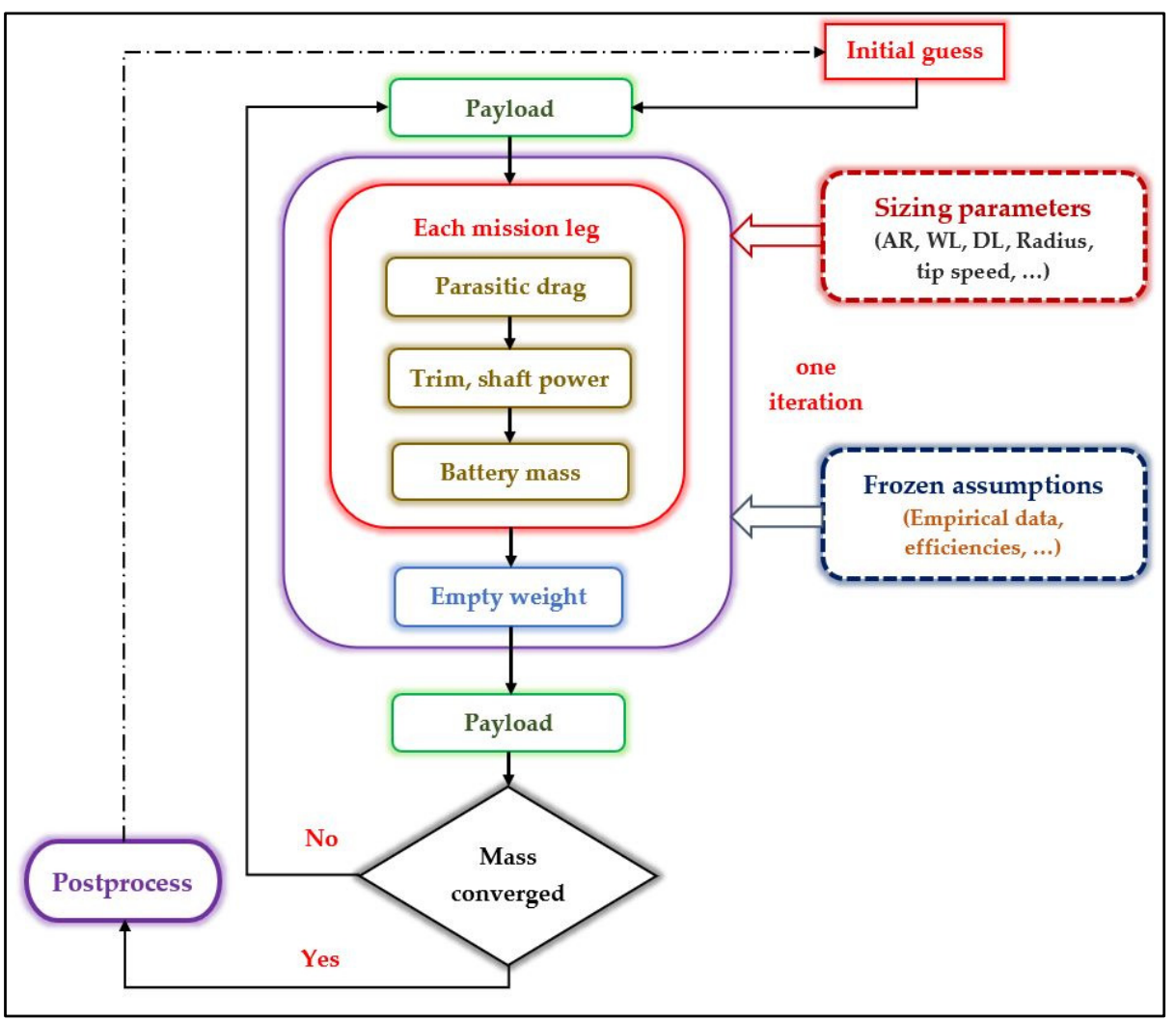

Figure 5. Iteration methodology flowchart.

\subsubsection{Iteration Process in the Estimation of the Weight of the Wing}

Initially, the weight estimation of the wing was made with the help of the relationship between the weight of the wing, aspect ratio and trapezoidal wing area. Mathematically, it is defined as

$$
\mathrm{W}_{\text {wing }}=0.036 \mathrm{~S}_{\mathrm{w}}^{0.758} \mathrm{~W}_{\mathrm{fw}}{ }^{0.0035} \mathrm{q}^{0.006} \lambda^{0.04}
$$


where $W_{\text {wing }}$ is the weight of the wing, $S_{w}$ is the trapezoidal wing area, $W_{f w}$ is the weight of fuel in the wing, $q$ is dynamic pressure at cruise and $\lambda$ is the taper ratio.

The process was iterated for various values of taper ratio to find the most effective condition. After successive iterations, it was concluded that this method of estimation of the weight of the wing depends on density which is a highly varying parameter [29]. Hence, the weight estimation was made using the relationship between weight loading factor and coefficient of lift, as the details of the airfoil were known.

\subsubsection{Iteration Process in the Estimation of the Weight of the Fuselage}

Similar to that of the wing, the dimensions and weight of the fuselage were estimated using the relationship between the weight of the fuselage, the wetted area of the fuselage and the L/D ratio. Equation (2) was used to estimate the weight of the fuselage.

$$
\mathrm{W}_{\text {fuselage }}=\left(0.052 \mathrm{~S}_{\mathrm{f}}^{1.086} \mathrm{~L}_{\mathrm{t}}^{-0.051} \mathrm{q}^{0.241}\right)+\mathrm{W}_{\text {press }}
$$

where $W_{\text {fuselage }}$ is the weight of the fuselage, $S_{f}$ is fuselage-wetted area, $L_{t}$ is tail length (wing quarter MAC to tail quarter MAC) and $W_{\text {press }}$ is weight penalty due to pressurization. On estimation, the weight of the fuselage was found to be impractical for the given dimensions; hence, it was calculated using the simplified version of the same equation. Furthermore, the same was analysed using the OpenVSP tool and the desired result was obtained.

\subsubsection{Iteration Process in the Estimation of the Weight of V-Tail and Flight Controls}

The sizing of the V-tail and flight controls was calculated using the relationship between the weight of the V-tail and the design gross weight, and the iterative values were the dimensions of the fuselage (the V-tail was analysed with the horizontal tail statistical equation because a V-tail is loaded for trim and manoeuvres, much like a horizontal tail).

$$
\begin{gathered}
\mathrm{W}_{\text {horizontal tail }}=0.016 \mathrm{q}^{0.168} \mathrm{~S}_{\mathrm{ht}}^{0.896} \lambda_{\mathrm{h}}{ }^{-0.02} \\
\mathrm{~W}_{\text {flight controls }}=0.053 \mathrm{~L}^{1.536} \mathrm{~B}_{\mathrm{w}}{ }^{0.371}
\end{gathered}
$$

where $S_{h t}$ is a horizontal tail area, $\lambda_{h}$ is taper ratio of the horizontal tail, $\mathrm{L}$ is fuselage structural length, $B_{\mathrm{w}}$ is wingspan. Equations (3) and (4) were helpful in determining the desired weight of the V-tail and the flight controls.

\subsubsection{Iteration Process in the Estimation of the Weight of the Landing Gear}

The weight of the landing gear was completely dependent on the weight of the main landing gear and nose landing gear. Both depend on the value of landing design gross weight, which was the initial iterative value. The equations used to estimate the weight of the landing gears were taken from [28].

\subsubsection{Payload Range Diagram}

The battery weight for the fully loaded aircraft was calculated using the total energy available. The total energy available $(741 \mathrm{MJ})$ was calculated by adding the energy required for each mission phase. The payload-range diagram (Figure 6) illustrates the range variation with decreasing number of passengers in the aircraft. This diagram is applicable for the range of a standard mission.

\subsection{Key Design Challenges}

The lack of operational electric vertical take-off and landing aircraft posed a design challenge. To solve this problem, it was assumed that the present eVTOL comes under the normal category of general aviation aircraft for the initial sizing of the aircraft.

One of the key design challenges was finding a suitable powerplant for the present eVTOL. After ruling out hydrogen fuel cells for their storage difficulties and lithium-cobalt batteries due to their low energy density, lithium-sulphur batteries were chosen. Using a 
battery as the powerplant means that most of the weight of the aircraft is confiscated by the battery. This was solved by taking the highest energy density possible for a lithium-sulphur battery, i.e., $600 \mathrm{Wh} / \mathrm{kg}$.

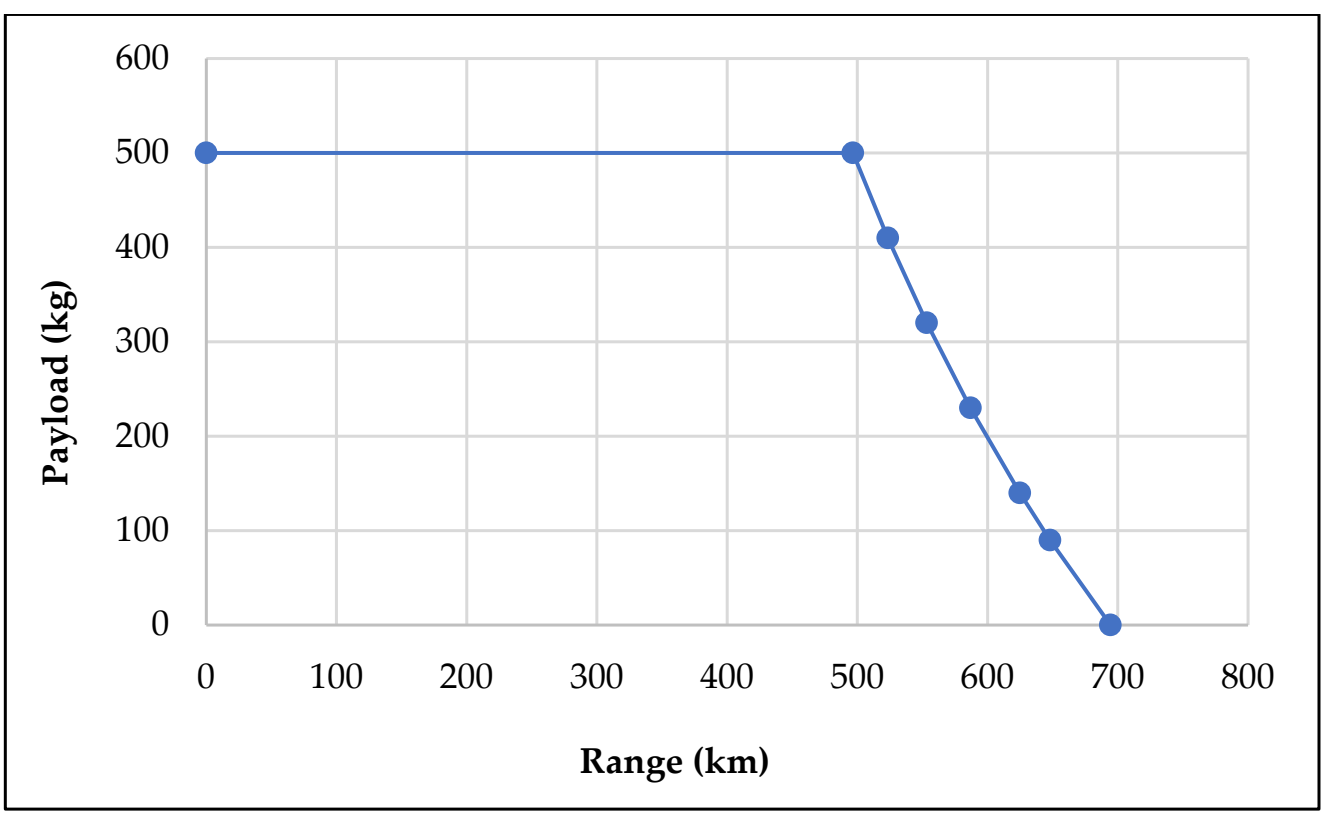

Figure 6. Payload versus range diagram.

Another design challenge was selecting a suitable number of propellers considering redundancy, reliability, weight and thrust. After the trade-off study, it was decided that six propellers - four on the wing and two on the tail-would be used. With propeller placement on the wing, ensuring the safety of the passengers during boarding is a difficult task. The propellers were placed as far away from the fuselage as possible to ensure safety and reduce noise during flight. This could not be done for the propellers on the V-tail. Hence, sufficient distance was given between the plane of the V-tail propellers and the passenger cabin. This is to ensure that a stray broken blade does not damage the passenger cabin in the event of an accident.

The wing placement on the fuselage was another major design challenge. The structure of the wing is supported by the wing box in the fuselage. Low- and mid-wing configurations were ruled out to provide clearance for the propellers. Selecting a suitable angle of incidence for the eVTOL that is suitable for all flight phases, such as climb, cruise and descent, was difficult. It was decided that an angle of 5.25 degrees will be used since it has the maximum lift-to-drag ratio and the angle of attack required for the cruise is within 5.25 degrees.

Designing the transition from vertical take-off to climb and then climb to cruise was also a challenge. This is due to the fact that during transition from vertical take-off to climb, the eVTOL must produce enough lift for rotors to transition from a vertical position to an angle of 45 degrees required for the climb. Therefore, it was assumed that the wing produced $75 \%$ of the required lift during the transition. This is one of the reasons why the angle of incidence was set high, so that there was no significant change in deck angle. This may reduce the discomfort experienced by the passengers during the transition. It was also found that the transition requires complex flight control software.

\section{Airfoil and Wing Planform Selection}

In the present design, the wing carries most of the load during most parts of the mission. The wing is initially designed using empirical formulas [28]. The three-dimensional tapered wing model is shown in Figure 7. To design the wing, the following assumptions were made: 
- The present eVTOL aircraft is taken to be flying at $2 \mathrm{~km}$ altitude in International Standard Atmosphere. The cruise speed is taken as $200 \mathrm{~km} / \mathrm{h}$.

- An aspect ratio of 8 was selected to reduce the span as much as possible. This will reduce the wing bending load due to placing the rotors on the wing. This will also enable the eVTOL to land on helipads.

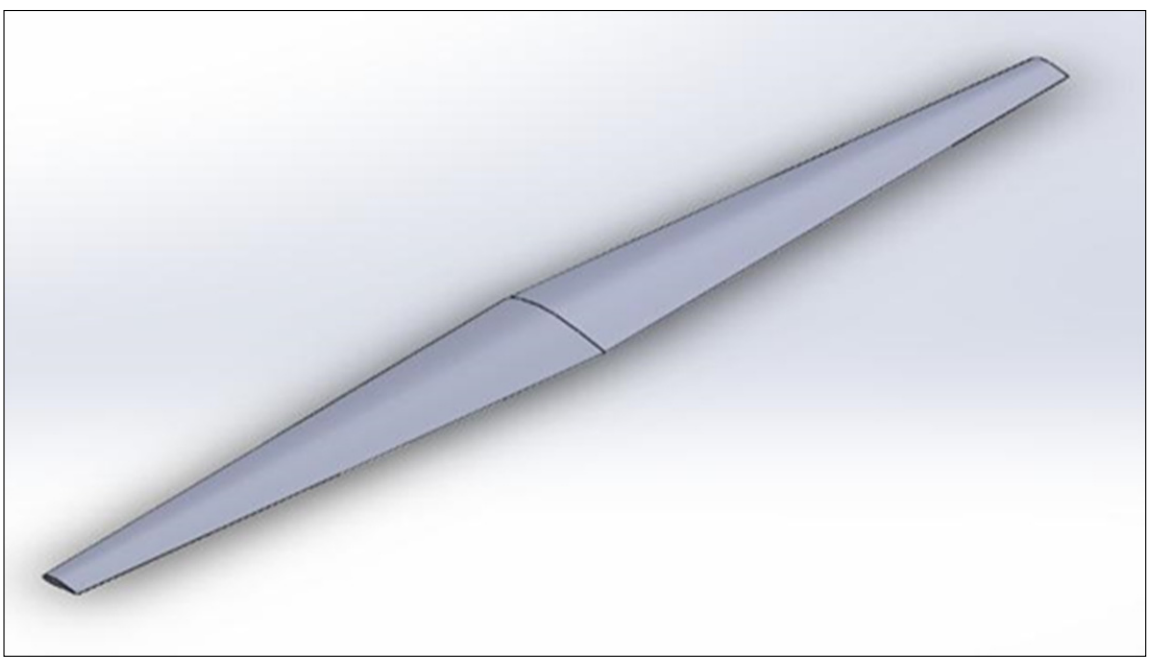

Figure 7. 3D wing model.

\subsection{Airfoil Selection}

The airfoil selected was NACA 64(3)-618 airfoil [30]. Thick airfoils were selected to enable battery storage in the wings. Furthermore, the NACA 6 series airfoils have a high lift-to-drag ratio and a high maximum coefficient of lift for a given angle of attack. Hence, NACA 64(3)-618 airfoil has $\mathrm{Cl}_{\max }$ at AOA 16 degrees.

\subsection{Estimation of Wing Parameters}

\subsubsection{Angle of Incidence}

The maximum aerodynamic efficiency occurs at 6 degrees angle of attack, after which stall occurs. Hence, an incident angle of 5.25 degrees was chosen to be well within the limit and get enough lift, especially during the climb. For stability, the tail must be able to produce counteracting moments during gusty wind conditions. Therefore, the tail angle of incidence is taken less than the wing angle of incidence. The stall characteristics occur when the angle of attack reaches $\alpha=12-5.25=6.75$ degrees because the limit of the drag bucket of the NACA 64(3)-618 occurs at $\alpha=12$ degrees [31].

\subsubsection{Twist Angle}

The tip of the wing tends to stall before the root which decreases the efficiency of the ailerons due to lack of flow over them. To counter this, a mechanical twist of -2 degrees was chosen.

\subsubsection{Three-Dimensional Lift Coefficient}

The lift slope of the airfoil was calculated to be 0.1. The Oswald Span Efficiency factor (e) was calculated as 0.8903 by using Equation (5). By using Equation (6), the threedimensional lift slope (a) was calculated to be 0.0796 . From this, the three-dimensional lift coefficient was calculated as 0.418 for an angle of incidence of 5.25 degrees. This is close 
to the design lift coefficient required for the cruise. The lift coefficient near stall angle of attack (i.e., max lift coefficient) was calculated as 0.796 .

$$
\begin{gathered}
\mathrm{e}=\frac{\mathrm{e}}{2-\mathrm{AR}+\sqrt{\left\{4+\mathrm{AR}^{2}\left(1+\tan ^{2} \Lambda_{\mathrm{tmax}}\right)\right\}}} \\
\mathrm{a}=\frac{\mathrm{a}_{0}}{1+\left(57.3 \frac{\mathrm{a}_{0}}{\pi \mathrm{eAR}}\right)}
\end{gathered}
$$

where $\mathrm{AR}$ is the aspect ratio, $\Lambda_{\mathrm{tmax}}$ is the wing sweep at the maximum thickness and $\mathrm{a}_{0}$ is airfoil lift slope.

\subsubsection{Taper Ratio}

Wing tip vortices decrease with the decrease in tip chord length; hence, a high taper ratio decreases vortices dramatically. However, it also decreases the structural integrity of the wing. Hence, a well-balanced taper ratio of 0.35 was chosen for a minimum induced drag from [32].

Figure 8 exhibits a schematic diagram of the wing.

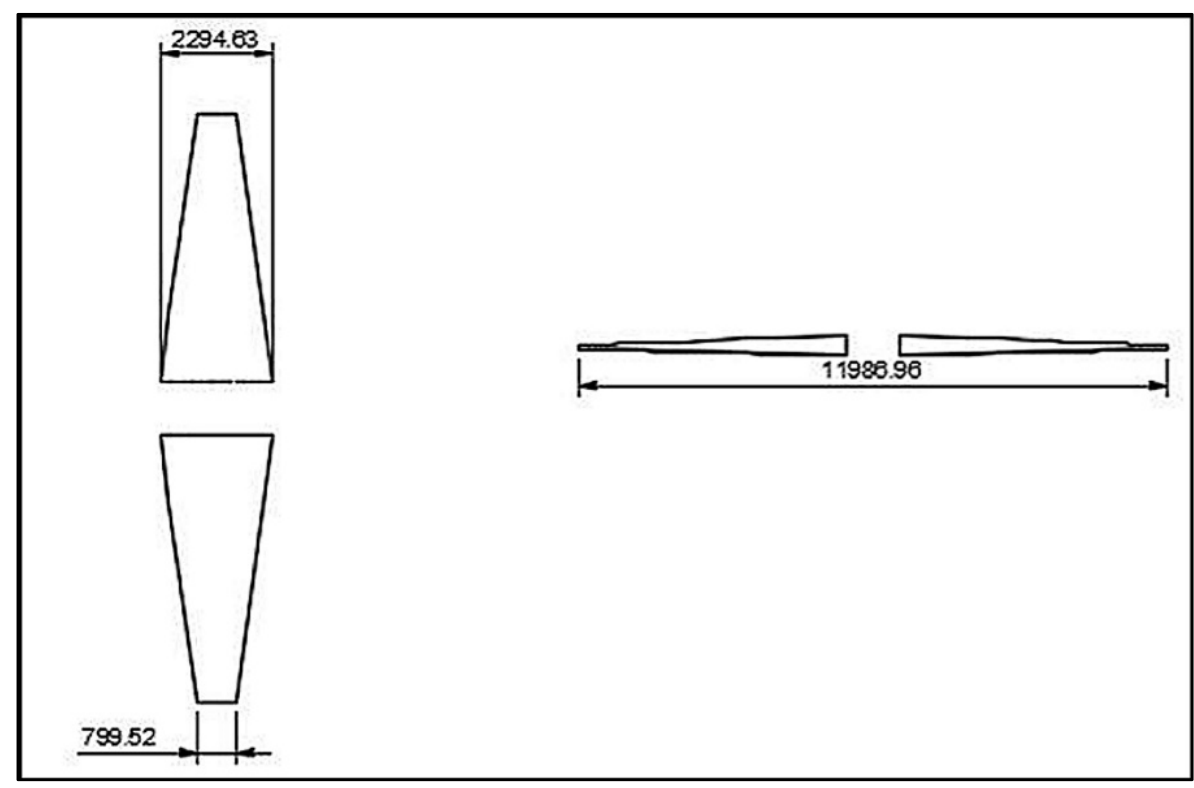

Figure 8. Wing schematic sketch made in Fusion 360.

Table 4 specifies the dimensions of the wing.

Table 4. Wing parameters.

\begin{tabular}{cc}
\hline Property & Dimensions \\
\hline Span & $11 \mathrm{~m}$ \\
Surface & $17 \mathrm{~m}^{2}$ \\
Mean chord & $1.55 \mathrm{~m}$ \\
Aspect ratio & 8 \\
Taper & 0.35 \\
Chord at root & $2.3 \mathrm{~m}$ \\
Chord at tip & $0.8 \mathrm{~m}$ \\
Twist & $-2^{\circ}$ \\
Angle of incidence & $5.25^{\circ}$ \\
Sweep at quarter chord & 0 \\
Mass & $200 \mathrm{~kg}$ \\
\hline
\end{tabular}




\section{Geometric Sizing}

\subsection{Fuselage}

The fuselage is the foremost important section of the aircraft. The width of the fuselage was decided by using the number of seats in a row, seat width and aisle width. The following were assumed according to the values for typical first-class seat measurements,

- $\quad$ Seat width, $0.5 \mathrm{~m}$;

- $\quad$ Aisle width, $0.5 \mathrm{~m}$;

- Fuselage length, $6 \mathrm{~m}$.

These were used to arrive at a fuselage width of $1.5 \mathrm{~m}$. The fuselage cross-section was taken to be circular with an outermost diameter of $1.5 \mathrm{~m}$. Fuselage fineness ratio of three was used to have minimum induced drag and a fuselage length of $5 \mathrm{~m}$ was reached [33].

The shape of the fuselage was selected with the aim of increasing the pilot's visibility of the immediate surroundings and the landing zone during near-rooftop missions. An upsweep of 15 degrees was designed in the rear of the fuselage for ease of cargo loading and smooth flow to decrease the pressure drag.

Prior to the calculation of the weight of the fuselage, it was modelled in OpenVSP. The parasitic drag feature was used to find the fuselage-wetted area. The fuselage-wetted area was used to find out the weight of the fuselage using the empirical formula for general aviation aircraft given in [28]. This finally led to a weight of $300 \mathrm{~kg}$. Since aluminium skin was the assumed material in [28] and considering the material for the present design as composite, an average weight reduction of $20 \%$ was achieved [34]. This led to a final value of $240 \mathrm{~kg}$.

The present eVTOL aircraft has a car-like interior design with a single pilot seat in the front and two rows of two seats for four people behind it. The luggage can be stored inside the compartment behind the passenger seats. Figure 9 portrays the internal layout of the fuselage.

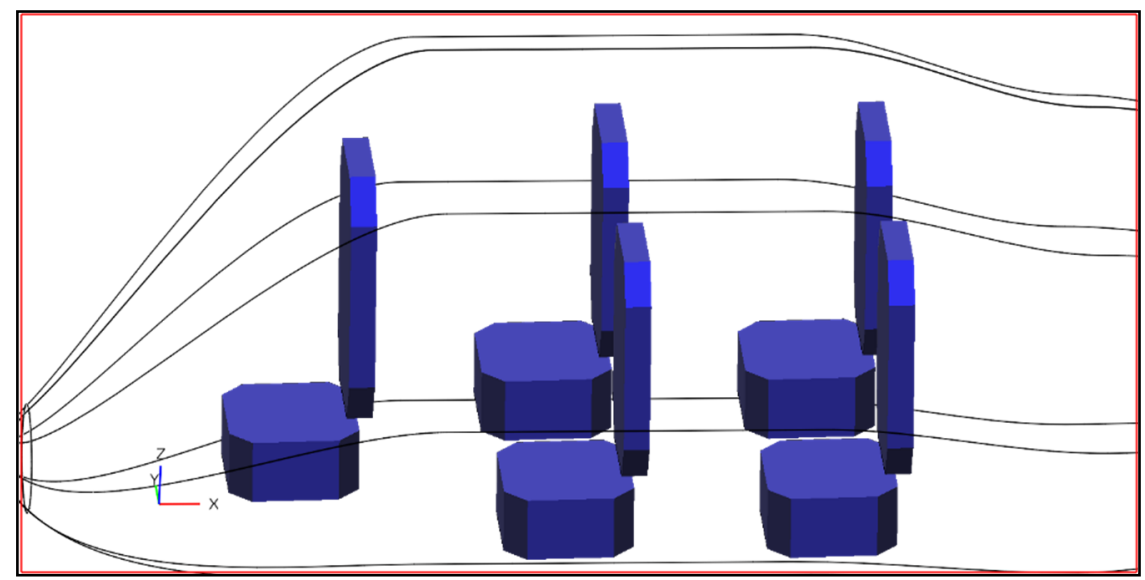

Figure 9. Fuselage internal layout of the present design.

The material for the interior components were meticulously selected considering thermal and acoustic insulation of the cabin. Other parameters such as durability, fire and static resistance and maximum cleanability were also considered. Proper care was taken to not increase the weight of the aircraft. The material chosen for the interior components is shown in Table 5.

Table 5. Materials used for the interior components.

\begin{tabular}{cccc}
\hline Facing & Core & Adhesive & Finishing \\
\hline Phenolic resin & Honeycomb-aramid fibre & Epoxy & Polyvinyl Chloride (PVC) \\
\hline
\end{tabular}


The fuselage was modelled in both SolidWorks and OpenVSP. Figure 10 shows the fuselage modelled in SolidWorks which was used for pressure analysis.

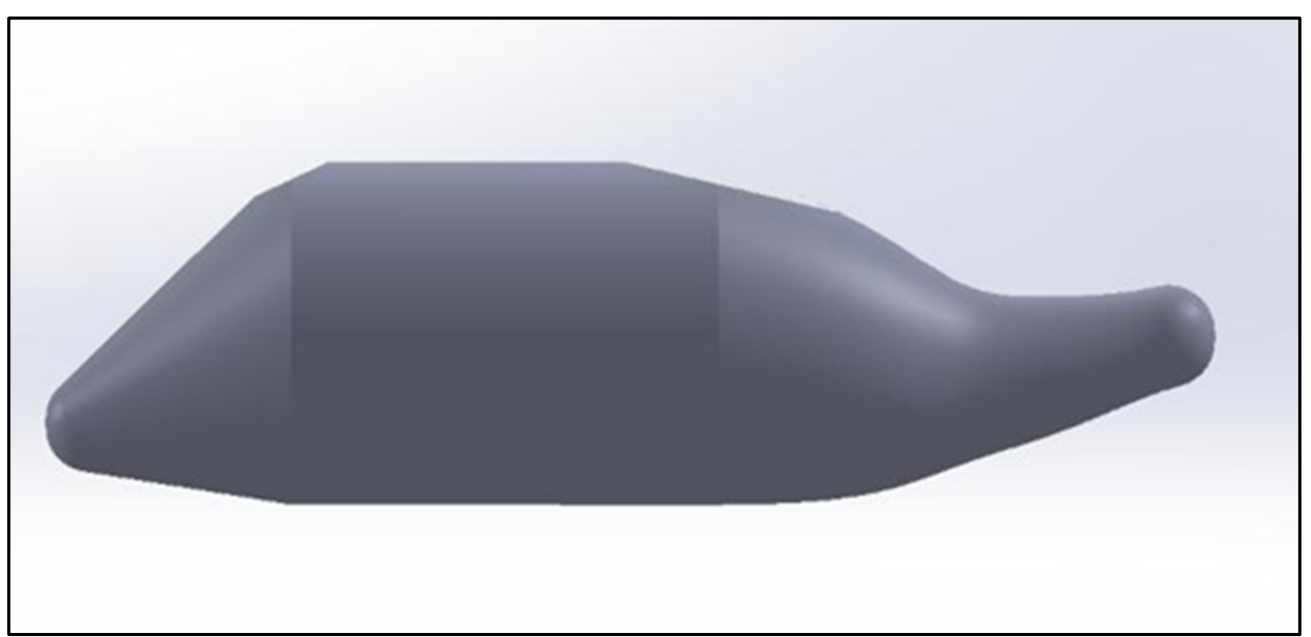

Figure 10. Fuselage 3D model.

\subsection{Tail Sizing and Configuration Selection}

The airfoil used for the V-tail is the NACA 0010 airfoil. Horizontal tail volume ratio and aspect ratio were taken as 0.7 and 3 from the historical data for general aviation aircraft. Equations (7)-(9) used for calculations were taken from [28]. The distance between the wing's mean geometric chord and quarter chord of the horizontal tail $\left(l_{\mathrm{HT}}\right)$ is given by Equation (7).

$$
\text { Tail moment arm } \mathrm{l}_{\mathrm{HT}}=\sqrt{ }\left\{\left(2 \mathrm{~V}_{\mathrm{HT}} \mathrm{S}_{\mathrm{ref}} \mathrm{c}_{\mathrm{ref}}\right) /\left(\prod\left(\mathrm{R}_{1}+\mathrm{R}_{2}\right)\right)\right\}
$$

The area of the horizontal tail $\left(\mathrm{S}_{\mathrm{HT}}\right)$ was calculated using Equation (8),

$$
\mathrm{S}_{\mathrm{HT}}=\left(\mathrm{V}_{\mathrm{HT}} \mathrm{S}_{\mathrm{ref}} \mathrm{C}_{\mathrm{ref}}\right) / 1_{\mathrm{HT}}
$$

The span of the horizontal tail $\left(\mathrm{b}_{\mathrm{HT}}\right)$ was calculated using Equation (9),

$$
\mathrm{b}_{\mathrm{HT}}=\sqrt{ }\left\{\mathrm{AR}_{\mathrm{HT}} \mathrm{S}_{\mathrm{HT}}\right\}
$$

where $\mathrm{V}_{\mathrm{HT}}$ is horizontal tail volume ratio, $\mathrm{S}_{\text {ref }}$ is wing reference area, $\mathrm{c}_{\text {ref }}$ is wing mean aerodynamic chord, $A R_{H T}$ is aspect ratio of horizontal tail, $R_{1}$ and $R_{2}$ are tail cone radius at the beginning and end, respectively. Since the tail is a V-tail, the values of $\mathrm{S}_{\mathrm{HT}}$ and $\mathrm{S}_{\mathrm{VT}}$ are chosen equal. The dihedral angle of the tail was selected as 45 degrees. The tail parameters are mentioned in Table 6.

Table 6. Tail parameters.

\begin{tabular}{cc}
\hline Tail Parameters & Dimensions \\
\hline Span & $4.439 \mathrm{~m}$ \\
Taper ratio & 0.7 \\
Aspect ratio & 3 \\
Average chord & $1.48 \mathrm{~m}$ \\
Dihedral angle & 45 degrees \\
\hline
\end{tabular}

\subsection{Powerplant Selection and Sizing}

The electric engines preferred for this aircraft comprise of two main parts: the electric motor and the tilt-rotor. The maximum power required (function of the rotation speed 
and torque needed) to produce the required thrust was significant in engine selection [35]. Table 7 shows the calculation for thrust required.

Table 7. Thrust required calculation.

\begin{tabular}{ccccc}
\hline $\begin{array}{c}\text { Velocity }(\mathbf{v}) \\
\mathbf{m} / \mathbf{s}\end{array}$ & $\begin{array}{c}\text { Coefficient of } \\
\text { Lift }\left(\mathbf{C}_{\mathbf{L}}\right)\end{array}$ & $\begin{array}{c}\text { Coefficient of } \\
\text { Drag }\left(\mathbf{C}_{\mathbf{D}}\right)\end{array}$ & $\begin{array}{c}\text { Lift-to-Drag } \\
\text { Ratio (L/D) }\end{array}$ & $\begin{array}{c}\text { Thrust Required } \\
\left(\mathbf{T}_{\mathbf{R}}\right) \mathbf{N}\end{array}$ \\
\hline 70 & 0.634 & 0.047 & 13.6 & 1226.25 \\
\hline
\end{tabular}

Performance criteria and propeller requirements to produce the required thrust were the deciding factors in motor choice. The working parameters such as RPM, power, torque, and other secondary parameters such as extended lifespan, less maintenance and high efficiency were considered. Amongst the several existing types of DC motors, brushless DC motors (BLDC) were the most appropriate for the design objectives. Motor performance parameters were mentioned in Table 8 [36].

Table 8. Motor performance parameters.

\begin{tabular}{ccccc}
\hline Type & Motor & Total Mass $(\mathbf{k g})$ & Maximum Speed (RPM) & Torque (N-m) \\
\hline BLDC & MP154120 & 20 & 9600 & 85.38 \\
\hline
\end{tabular}

\subsection{Propeller Selection}

The propeller for the design was chosen based on power required. The following specifications of the selected propeller were taken from [37]:

- $\quad$ Number of blades in one engine = 3;

- $\quad$ Blade diameter = $1.50 \mathrm{~m}$;

- Propeller collective pitch $=5^{\circ}$;

- Hub diameter $=0.40 \mathrm{~m}$;

- $\quad$ Root twist $=32^{\circ}$; Airfoil used: NACA 64-935;

- $\quad$ Tip twist $=8^{\circ}$; Airfoil used: NACA 64-212.

\subsection{Landing Gear Sizing}

For the aptest landing gear configuration, the tricycle configuration was selected. The two main wheels are located behind the CG point to withstand the main load. Tricycle landing gear helps keep the aircraft well balanced and uninclined when at rest. This helps in easy ground manoeuvres during taxiing and provides better visibility to the pilot. Furthermore, it is not a discomfort to the passengers. The retractable landing gear is suitable for this eVTOL aircraft. It has advantages such as drag reduction when it is retracted into the fuselage and an increase in overall velocity, which also provides an enhanced aircraft performance when compared to the fixed landing gear configuration. Furthermore, wheeled gears have better shock-absorbing properties to assure a comfortable travel experience for passengers. Hence, oleo-pneumatic trailing-link shock absorbers with high efficiency and energy dissipation were used to connect the wheels of the landing gear. The distance between the main and nose landing gear and the distance between the two main wheels were selected to deliver a stable (longitudinal and lateral) position for the aircraft when at rest. The wheelbase distance for nose landing gear is $1 \mathrm{~m}$ from the front fuselage and two main landing gears are placed at $2.5 \mathrm{~m}$ from the nose landing gear. The distance between the two main wheels is $1 \mathrm{~m}$. The tire size is considered by using the maximum static load (during vertical landing) and the essential inflation pressure. As the aircraft will operate from runways and helipads (rooftops) built of concrete or asphalt, the maximum inflation pressure is 75 psi [38]. Table 9 shows the tire selection specifications [39]. 
Table 9. Tire selection specifications.

\begin{tabular}{ccc}
\hline Tire Selection & Main Gear & Nose Gear \\
\hline Outer diameter [m] & 0.34 & 0.33 \\
Width [m] & 0.15 & 0.12 \\
Rim diameter [m] & 0.101 & 0.101 \\
Maximum load [kg] & 1600 & 800 \\
Inflation pressure [kPa] & 930 & 792 \\
Static loaded radius [m] & 0.13 & 0.13 \\
\hline
\end{tabular}

As far as sizing is considered, the landing gear equations were referred from Raymer [28] and upon ballparking various values, the weights of main and nose landing gear were calculated using Equations (10) and (11), respectively,

- $\quad$ Ultimate landing load factor $\left(\mathrm{N}_{\mathrm{L}}\right)=$ limit load factor of gear $\left(\mathrm{N}_{\text {gear }}\right) \times 1.5=20$;

- Extended length of main landing gear $\left(\mathrm{L}_{\mathrm{m}}\right)=0.6 \mathrm{~m}$;

- Extended length of nose landing gear $\left(\mathrm{L}_{n}\right)=4 \mathrm{~m}$;

$$
\begin{gathered}
\text { Main landing gear weight }=0.095\left(\mathrm{~N}_{\mathrm{L}} \mathrm{W}\right)^{0.768}\left(\mathrm{~L}_{\mathrm{m}} / 12\right)^{0.409} \\
\text { Nose landing gear weight }=0.125(20 \times 1.5 \times 1500)^{0.566}\left(\mathrm{~L}_{\mathrm{n}} / 12\right)^{0.845}
\end{gathered}
$$

- $\mathrm{W}_{\mathrm{MLG}}=47.47 \mathrm{~kg}$;

- $\mathrm{W}_{\mathrm{NLG}}=9.64 \mathrm{~kg}$.

Total weight of tricycle landing gear $=\mathrm{W}_{\mathrm{MLG}}+\mathrm{W}_{\mathrm{NLG}}=57.11 \mathrm{~kg}$.

\subsection{Flight Controls/Avionics Sizing}

The weight of flight controls was calculated using Equation (12),

$$
\mathrm{W}_{\text {Flight controls }}=0.053 \mathrm{~L}^{1.536} \mathrm{~B}_{\mathrm{W}}{ }^{0.371}\left(\mathrm{~N}_{\mathrm{z}} \mathrm{W}_{\mathrm{dg}} 10^{-4}\right)^{0.8}
$$

- $\quad$ Fuselage structural length $(\mathrm{L})=8.23 \mathrm{~m}$;

- Wing span $\left(\mathrm{B}_{\mathrm{w}}\right)=10.97 \mathrm{~m}$;

- Weight of flight controls $\left(\mathrm{W}_{\text {flight controls }}\right)=26.23 \mathrm{~kg}$.

where $N_{z}$ is the ultimate load factor and $W_{d g}$ is the design gross weight. The following dimensions of the control surfaces were arrived following the concepts discussed in Raymer [28] and tabulated in Table 10.

Table 10. Control surface dimensions.

\begin{tabular}{ccc}
\hline Control Surfaces & Length $(\mathrm{m})$ & Chord $(\mathrm{m})$ \\
\hline Ailerons & 2.1 & 0.2 \\
Ruddervators & 1.99 & 0.2 \\
Flaps & 1.5 & 0.345 \\
\hline
\end{tabular}

\subsection{Cargo Mode}

The cargo provisions for the aircraft are given behind the seats of the aircraft. The baggage can be stored in the cargo compartment behind the seats of the aircraft. The cargo compartment is $0.745 \mathrm{~m}$ long, $1 \mathrm{~m}$ high and $1.044 \mathrm{~m}$ wide. The volume of the cargo compartment is 0.8 cubic metres. The cargo bay can be accessed via a cargo door located at the cargo bay door behind the aircraft.

The cargo volume per passenger is 0.2 cubic metres. The maximum cargo that can be carried in air taxi mode with all passengers is $50 \mathrm{~kg}$. The aircraft can be switched from air-taxi mode to cargo mode by folding or removing the seats. In cargo mode, the seats are folded which increases the cargo compartment volume by 0.86 cubic metres. The total cargo volume in cargo mode is 1.66 cubic metres. The maximum cargo that can be carried 
in cargo mode is $410 \mathrm{~kg}$. The types of goods that can be transported include electronics, consumer and retail goods, toys, clothing, and textiles. Both the air cargo and air taxi modes are shown in Figures 11 and 12, respectively.

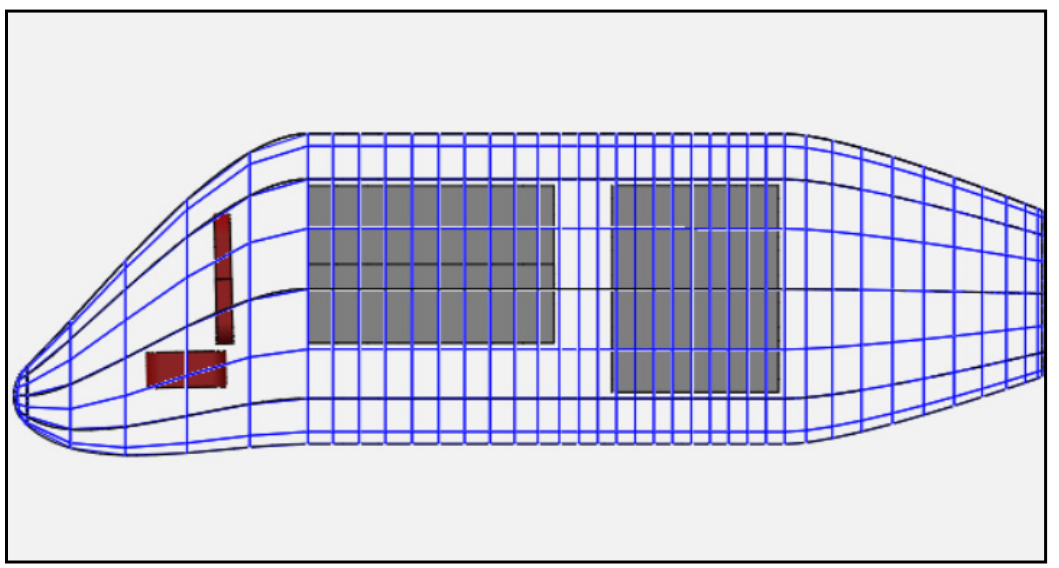

Figure 11. Schematic of cargo compartment volume (air-cargo mode).

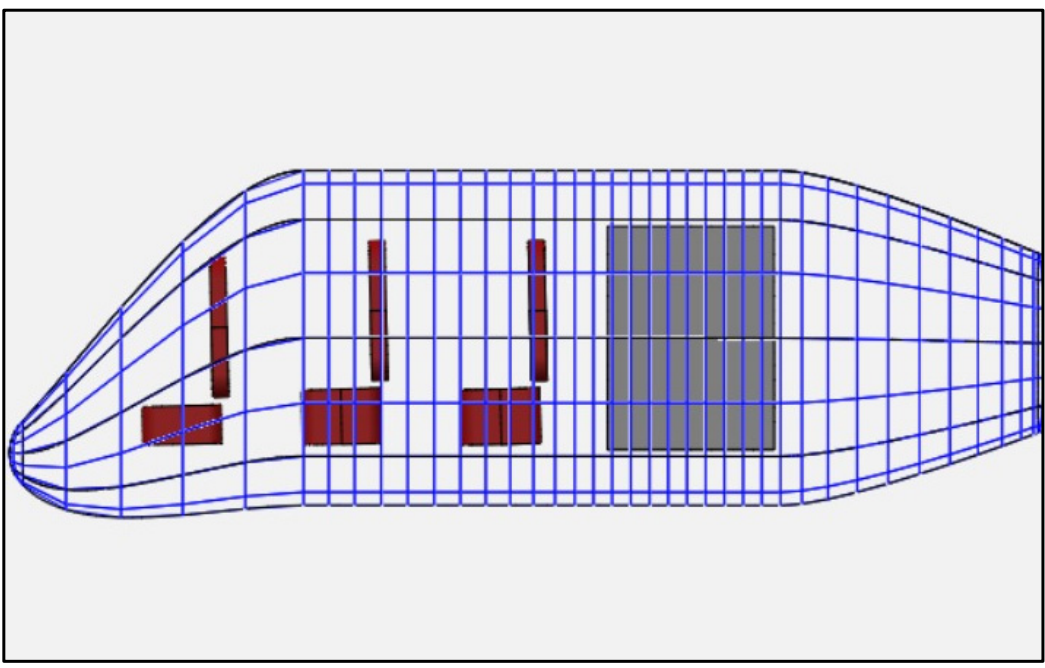

Figure 12. Schematic of cargo compartment volume (air-taxi mode).

\section{Design Parameters}

\subsection{Constraint Analysis}

A constraint diagram was drawn to select the power-to-weight ratio and wing loading required. The various curves drawn were for the cruise, climb, vertical climb and stall constraints. A stall velocity of $35 \mathrm{~m} / \mathrm{s}$ was used as the stall constraint. Figure 13 shows that the design region is above the vertical climb line. The highest possible wing loading and the lowest possible power loading in the design region were designated. A wing loading of $1000 \mathrm{~N} / \mathrm{m}^{2}$ and a power-to-weight ratio of 16 were selected. It can also be seen that the coefficient of lift required at the design point is 1.6 for a wing loading of $1000 \mathrm{~N} / \mathrm{m}^{2}$.

\subsection{Sensitivity Analysis}

A sensitivity analysis was conducted between the parameters maximum cruise speed, stall speed, maximum coefficient of lift and wing area using a carpet plot (Figure 14). With this carpet plot and the constraint diagram, the following values were concluded:

- Maximum cruise speed, $73.352 \mathrm{~m} / \mathrm{s}$;

- $\quad$ Stall speed, 35 m/s;

- Maximum coefficient of lift, 1.6; 
- Wing area, $17 \mathrm{~m}^{2}$.

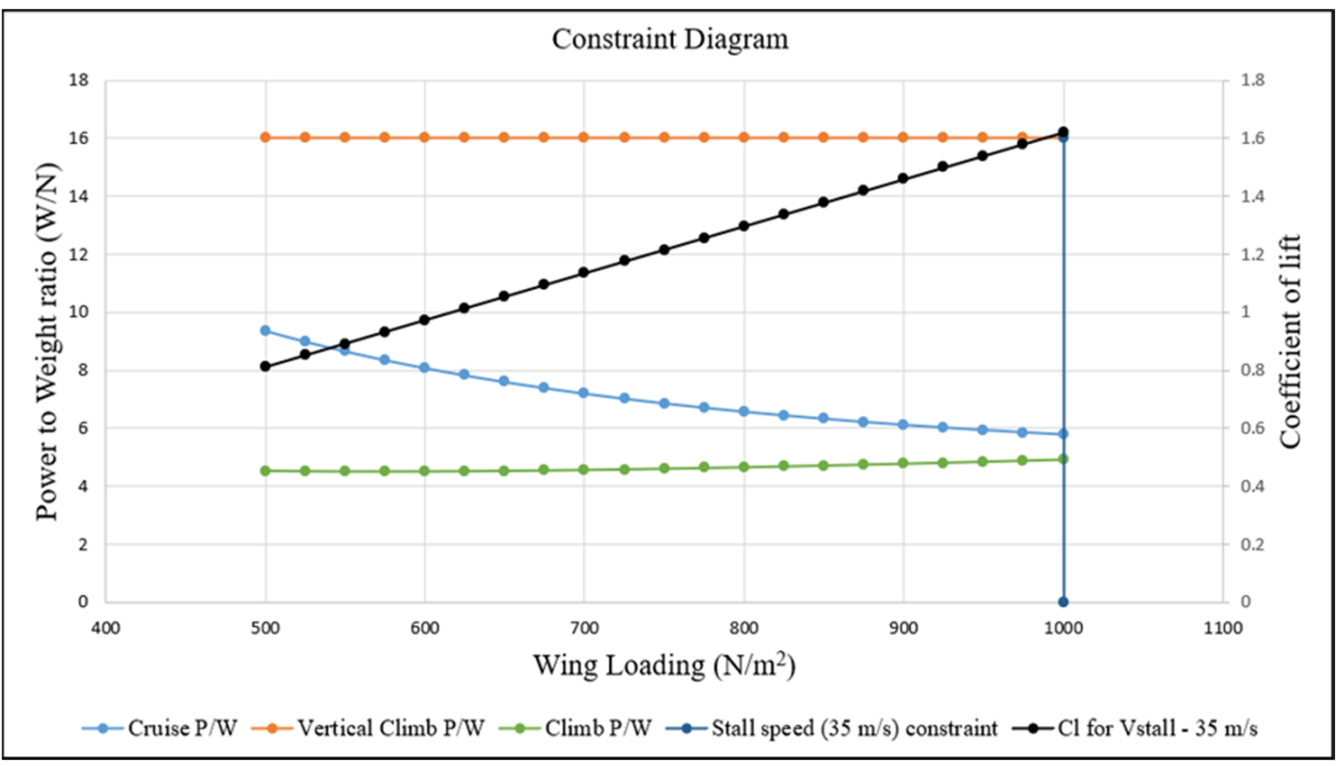

Figure 13. Constraint analysis diagram.

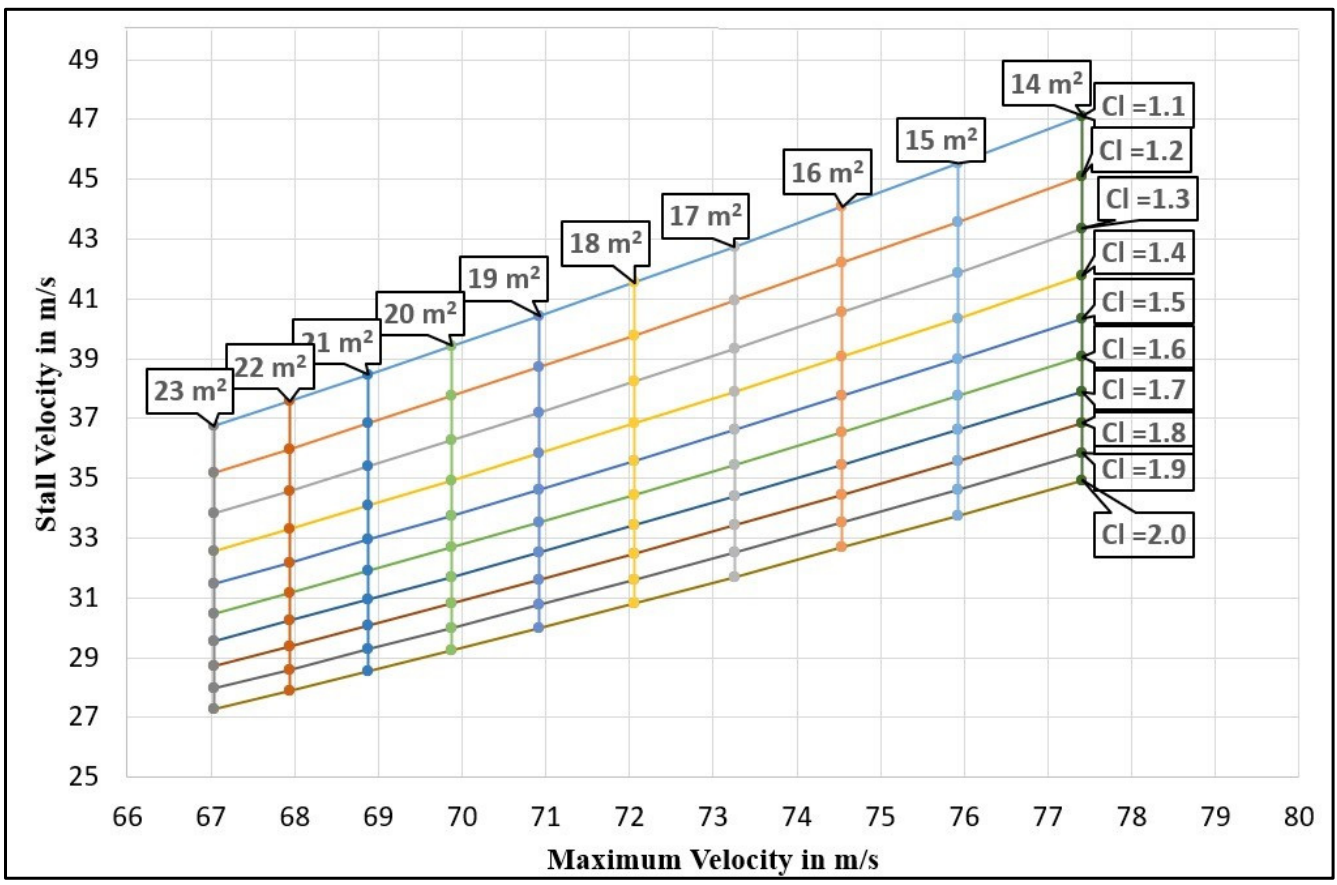

Figure 14. Stall speed-maximum cruise speed carpet plot.

In order to find the variation of the battery weight with respect to the specific energy of the battery, a sensitivity analysis was conducted. Since the battery weight itself is the function of the total aircraft weight, a bisection method was used to iterate the battery weight at each value of specific energy density. These values were plotted on the graph in Figure 15. It is observed that there is a decrease in battery weight with an increase in specific energy. The practical achievable energy density for lithium-sulphur batteries within the 2030s is $600 \mathrm{Wh} / \mathrm{kg}$. Hence, this was used as the maximum value in the analysis. 


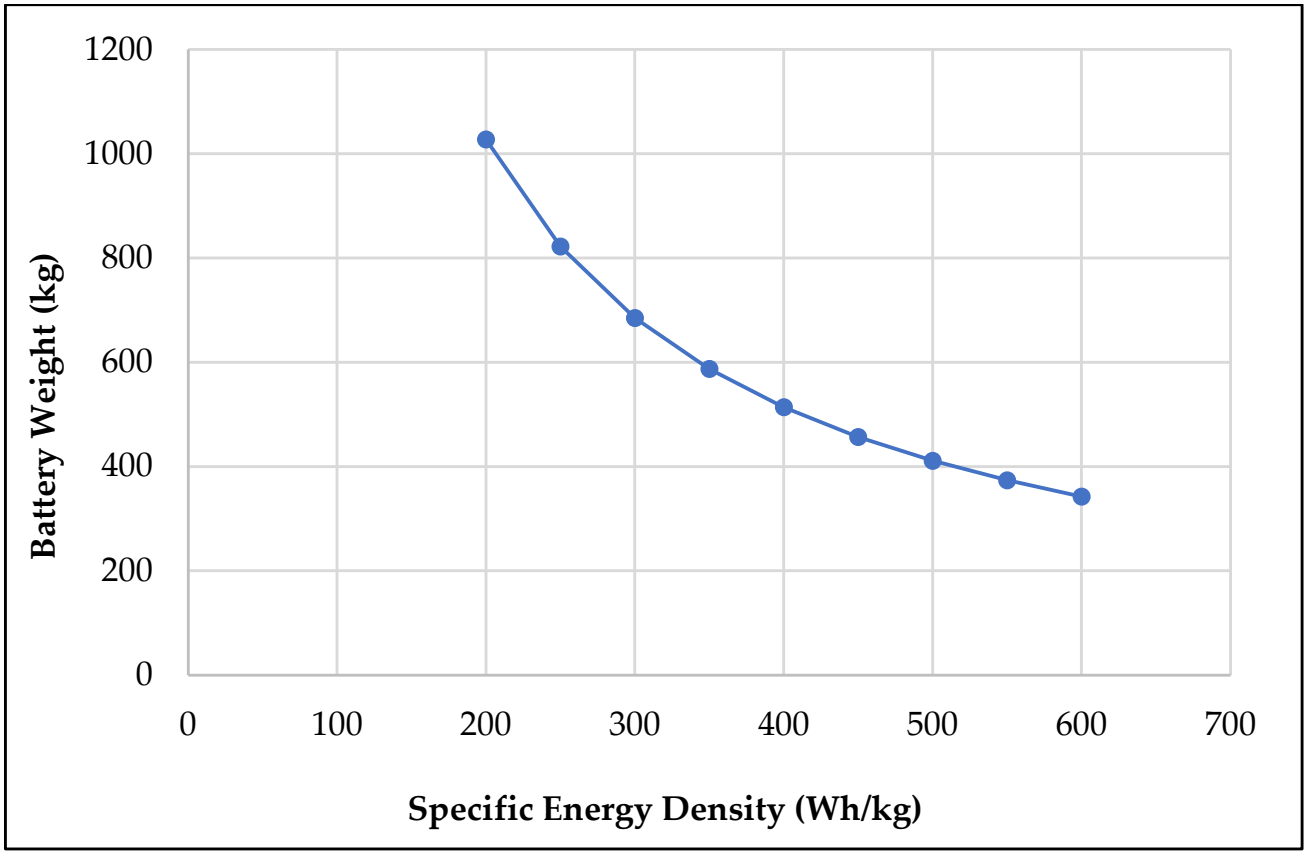

Figure 15. Battery weight versus specific energy density of battery.

\section{Component Placement and Centre of Gravity Estimation}

\subsection{Battery Location}

The battery was decided to be placed in the wings as this may facilitate cooling of the battery systems using outside air. A volumetric energy density of $1000 \mathrm{Wh} / \mathrm{L}$ was assumed to calculate the volume of the battery from the total energy that was previously calculated. Furthermore, the volume required for the cooling and housing system was reached by assuming it to be equal to the volume of the battery. This finally led to the volume of each battery pack as 0.253 cubic metres. Figure 16 shows the schematic of the battery location in the wing.
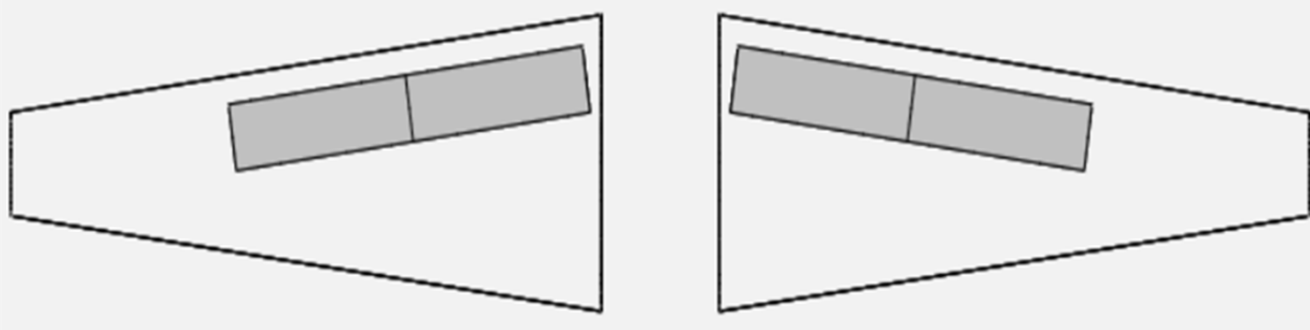

Figure 16. Schematic of battery location in the wing (in OpenVSP).

\subsection{Electric Motor Placement}

The engine was placed at the mid-span of both wings for the following reasons:

- To ensure that the crew and the passenger compartment are not within 5 degrees of the propeller disk in the event of a blade hurled towards the fuselage.

- The propeller must be as far as possible from the fuselage to avoid disturbance due to noise and aid in smooth flight. 
- The span loading effect created will reduce the wing structural weight.

The engine was placed in such a way that

- The propeller hub and electric motor is able to rotate freely without any problems to facilitate various manoeuvres.

- The wing does not interfere with the thrust produced by the propeller during vertical flight.

- The fuselage drag is reduced by repositioning the fuselage away from the propeller's wake region.

Figure 17 shows the OpenVSP model (top view) with accurate location of motors.

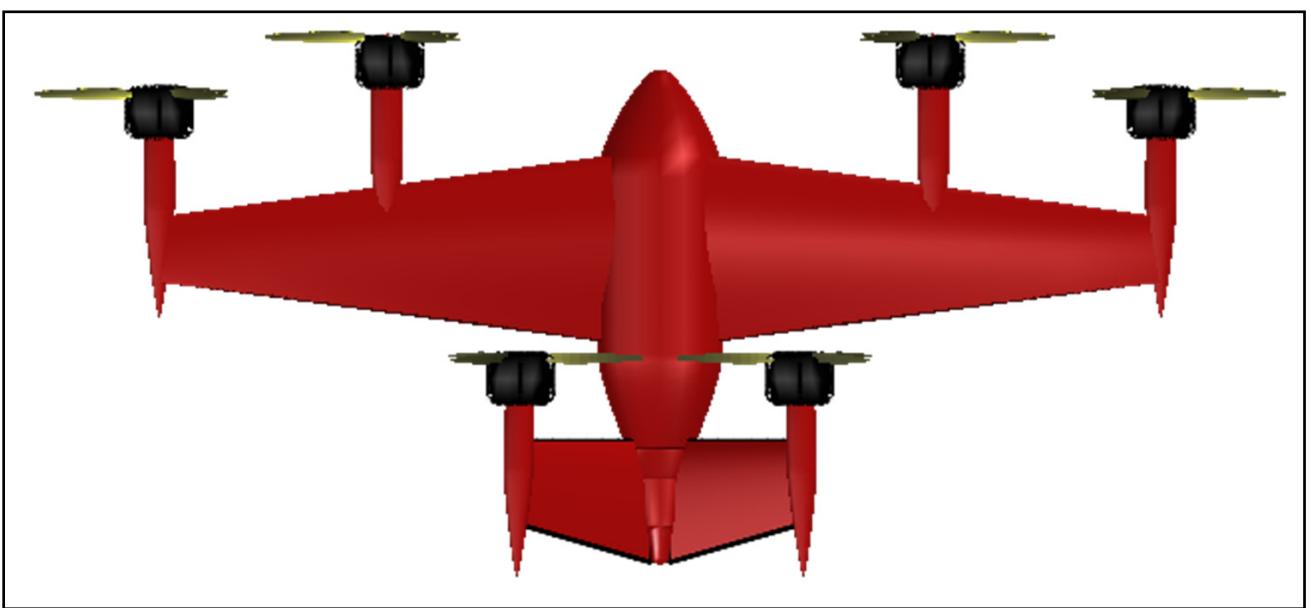

Figure 17. OpenVSP model (top view) with motor locations.

\subsection{Centre of Gravity (Initial Estimate)}

The initial estimation of the centre of gravity was conducted with the help of OpenVSP. The location of the component loads was taken from OpenVSP. Subsequently, the centre of gravity was calculated using Equations (13)-(19). The values $X_{n}, Y_{n}$ and $Z_{n}$ for different components were obtained from OpenVSP. The already calculated weights $W_{n}$, for components were used.

Moments about the origin of the coordinate system,

$$
\begin{aligned}
& M_{x}=\left(W_{1} X_{1}\right)+\left(W_{2} X_{2}\right)+\left(W_{3} X_{3}\right)+\ldots+\left(W_{n} X_{n}\right) \\
& M_{y}=\left(W_{1} Y_{1}\right)+\left(W_{2} Y_{2}\right)+\left(W_{3} Y_{3}\right)+\ldots+\left(W_{n} Y_{n}\right) \\
& M_{z}=\left(W_{1} X_{1}\right)+\left(W_{2} X_{2}\right)+\left(W_{3} X_{3}\right)+\ldots+\left(W_{n} Z_{n}\right)
\end{aligned}
$$

Location of centre of gravity,

$$
\begin{aligned}
& \mathrm{X}_{\mathrm{cg}}=\mathrm{M}_{\mathrm{x}} / \mathrm{W}_{\text {tot }} \\
& \mathrm{Y}_{\mathrm{cg}}=\mathrm{M}_{\mathrm{y}} / \mathrm{W}_{\text {tot }} \\
& \mathrm{Z}_{\mathrm{cg}}=\mathrm{M}_{\mathrm{z}} / \mathrm{W}_{\text {tot }}
\end{aligned}
$$

where

$$
\mathrm{W}_{\text {tot }}=\mathrm{W}_{1}+\mathrm{W}_{2}+\mathrm{W}_{3}+\ldots+\mathrm{W}_{\mathrm{n}}
$$

The centre of gravity of the empty aircraft was obtained as $X_{\mathrm{cg}}=2.089 \mathrm{~m}, \mathrm{Y}_{\mathrm{cg}}=0$ $\mathrm{m}$ and $Z_{\mathrm{cg}}=0.11 \mathrm{~m}$. The $C G$ shifts from $X_{\mathrm{cg}}=2.089 \mathrm{~m}$ at empty state to $X_{\mathrm{cg}}=2.21 \mathrm{~m}$ at maximum payload. Figure 18 shows the location of the CG in the OpenVSP view. 


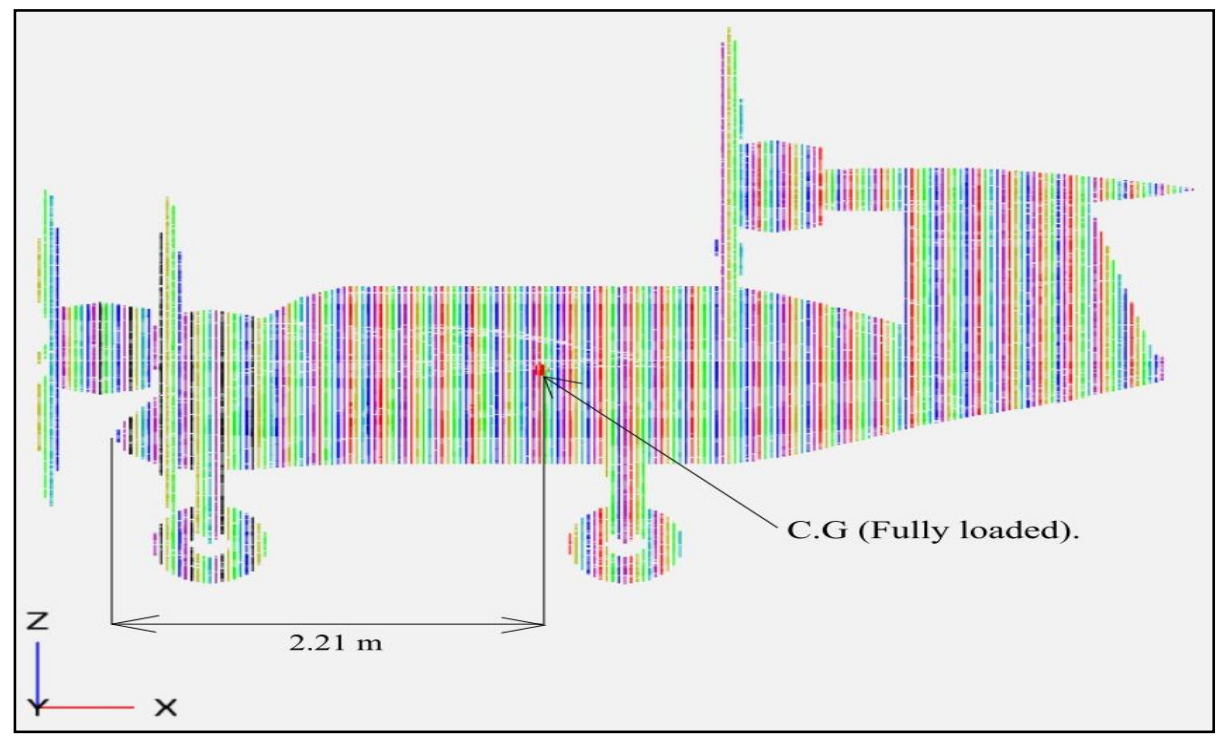

Figure 18. OpenVSP view with CG.

\section{Aerodynamic Analysis}

\subsection{Lift Curve}

The proposed design's wing was modelled (Figure 19) to get the three-dimensional lift coefficient $\left(C_{L}\right)$. Figure 20 exhibits the graph of the lift coefficient versus the angle of attack for the wing.

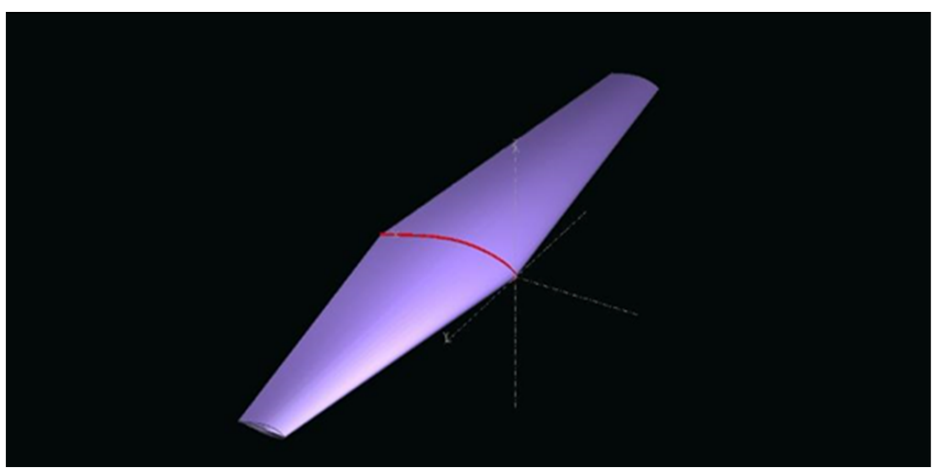

Figure 19. Model of the wing.

\subsection{Total Parasite Drag}

The total parasitic drag was calculated through the component build-up method. Equations (20)-(23) were used to calculate the total parasitic drag [28].

$$
\begin{gathered}
D_{\text {total }}=\sum D_{\text {comp }}+D_{\text {L\&p }}+D_{\text {misc }} \\
D_{\text {comp }}=D_{S F}+D_{\text {form }}+D_{\text {interference }} \\
D_{S F}=c_{f}\left(S_{\text {wet }} S_{\text {ref }}\right) \\
D_{\text {form }}=\text { FF } D_{S F}
\end{gathered}
$$

where $\mathrm{D}_{\text {misc }}$ is the drag due to miscellaneous items, $\mathrm{D}_{\mathrm{L} \& \mathrm{p}}$ is the drag due to leakages and protuberances, $D_{\text {comp }}$ is a component drag, $D_{S F}$ is skin friction drag, $c_{f}$ is coefficient of friction, $\mathrm{S}_{\text {wet }}$ is wetted surface area and FF is the form factor. Drag contributions by several components of the eVTOL were tabulated in Table 11. 


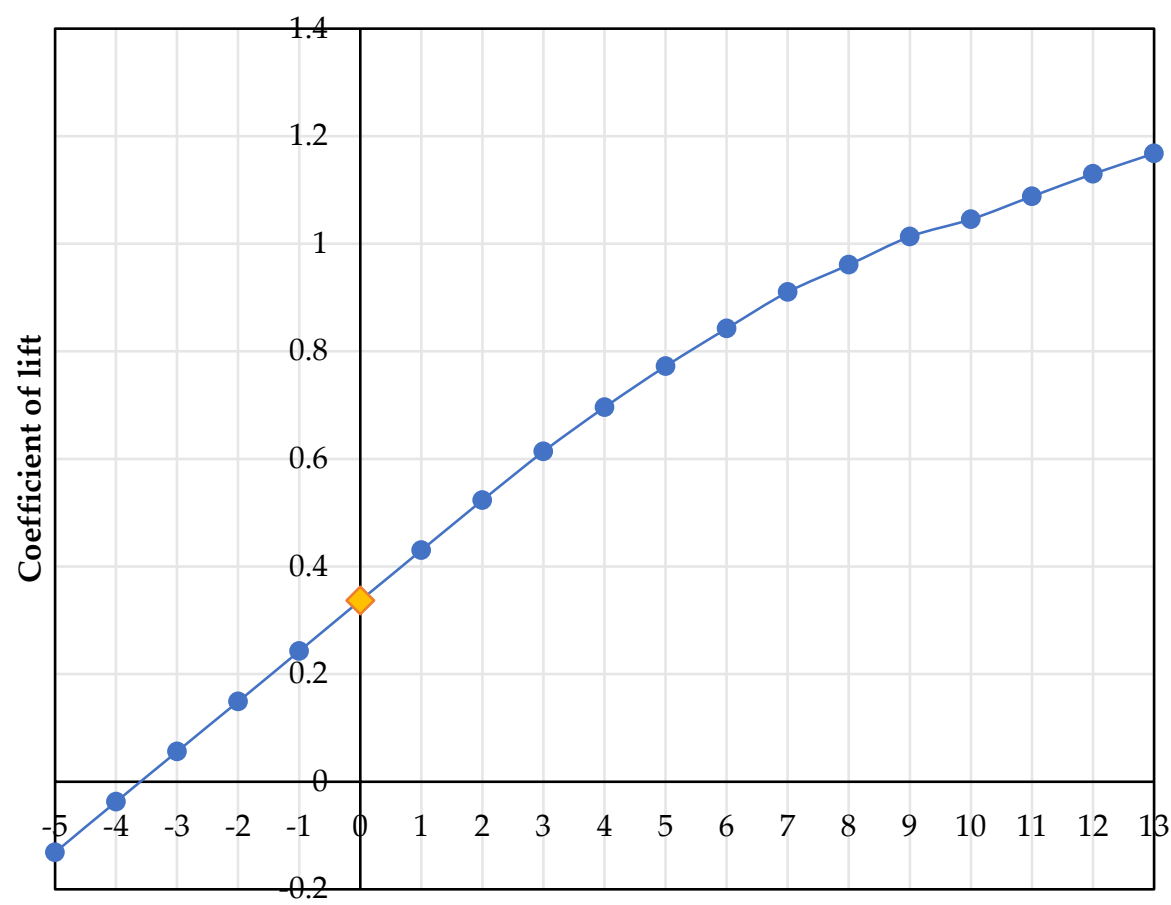

Angle of attack (degrees)

Figure 20. Lift coefficient for the wing versus angle of attack.

Table 11. Drag contributions by various components.

\begin{tabular}{ccc}
\hline Component & $\begin{array}{c}\text { Coefficient of Parasitic Drag from } \\
\text { Component Build-Up Method }\end{array}$ & $\begin{array}{c}\text { OpenVSP Parasitic Drag } \\
\text { Coefficient }\end{array}$ \\
\hline Wing & 0.00965 & 0.0097 \\
Fuselage & 0.007 & 0.006 \\
V-Tail & 0.003 & 0.0038 \\
Propeller Hubs & 0.0026 & 0.00264 \\
Miscellaneous & 0.0137 & - \\
\hline Total & 0.0359 & 0.02214 \\
\hline
\end{tabular}

It is important to note that the miscellaneous drag is due to the fuselage upsweep angle of 15 degrees. It was calculated using Equation (24),

$$
\mathrm{D} / \mathrm{q}=\mathrm{C}_{\mathrm{D}} \mathrm{S}_{\text {ref }}=3.83 \mathrm{u}^{2.5} \mathrm{~A}_{\max }
$$

where $S_{\text {ref }}$ is the wing reference area, $q$ is dynamic pressure, $u$ is upsweep angle and $A_{\max }$ is maximum fuselage cross-sectional area [28].

\subsection{Calculation of Induced Drag}

The induced drag was calculated using the Oswald efficiency method. Equation (25) was used for the calculation of the total drag for mission phases of the aircraft.

$$
\mathrm{C}_{\mathrm{D}}=\mathrm{C}_{\mathrm{D} 0}+\mathrm{kC}_{\mathrm{L}}^{2}
$$

where $C_{D}$ is the coefficient of drag, $C_{D 0}$ is the zero-lift drag coefficient, $k$ is the drag factor due to lift and $\mathrm{C}_{\mathrm{L}}$ is the coefficient of lift [28].

\subsection{Lift Estimation}

At a steady level phase, the lift is equal to the weight of the aircraft. The lift coefficient is a function of wing surface area and the airspeed of the aircraft. The wing 3D model was 
designed in OpenVSP and was analysed using the "vspaero" feature of OpenVSP. Table 12 shows the boundary conditions for which the lift coefficient was determined.

Table 12. Boundary conditions for lift coefficient calculations.

\begin{tabular}{cc}
\hline Mode & Cruise mode \\
Velocity & $70 \mathrm{~m} / \mathrm{s}$ \\
Pressure & $101,235 \mathrm{~Pa}$ \\
Altitude & Sea level conditions \\
Wing surface area & $16.8594 \mathrm{~m}^{2}$ \\
Reynold's number & $7.42 \times 10^{6}$ \\
Wing incidence angle & $5.25^{\circ}$ \\
\hline
\end{tabular}

The coefficient of lift is found out to be 0.4791 at the zero angle of attack from the lift polar, as shown in Figure 21.

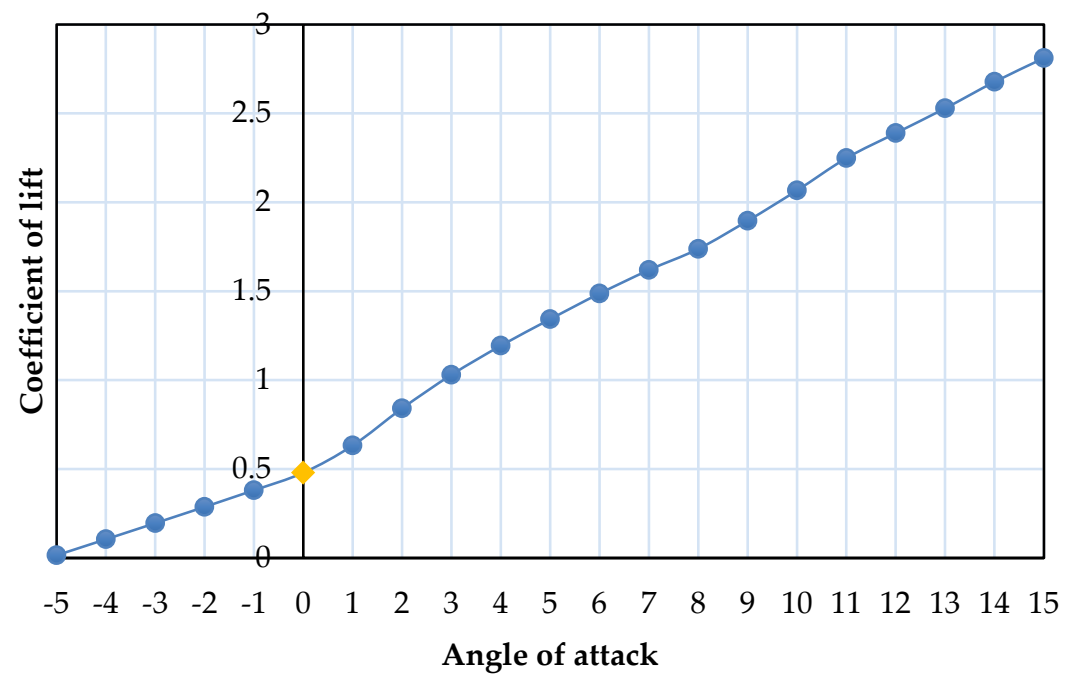

Figure 21. Coefficient of lift (analysis) versus angle of attack.

\subsection{Parasite Drag}

The parasitic drag is the drag that acts on the aircraft when it travels through the fluid. The sum of form drag and skin friction drag is the parasitic drag. The eVTOL aircraft was modelled for cruise mode in OpenVSP. The parasitic drag was calculated using the "parasite drag" feature of OpenVSP. Table 13 shows the parasitic drag for various altitudes. Figure 22 shows the pie chart of major contributors of parasite drag.

Table 13. Parasitic drag calculations.

\begin{tabular}{ccccc}
\hline Serial Number & Mode & Altitude $(\mathbf{m})$ & Velocity $(\mathbf{m} / \mathbf{s})$ & Parasitic Drag $\left(\mathbf{C d}_{\mathbf{0}}\right)$ \\
\hline 1. & Cruise & Sea level & 70 & 0.03008 \\
2. & Cruise & 2000 & 70 & 0.03085 \\
\hline
\end{tabular}

\subsection{Total Drag}

The total drag is the addition of both parasitic drag and lift induced drag. The total drag coefficient is a function of the frontal projected area and the airspeed of the aircraft. The eVTOL model without the propeller was designed in OpenVSP and was examined using the "vspaero" feature of OpenVSP. The vortex lattice method was used for calculating the drag coefficient. The drag coefficient was determined with the following boundary conditions and were tabulated in Table 14. 


\section{PARASITE DRAG} CONTRIBUTORS

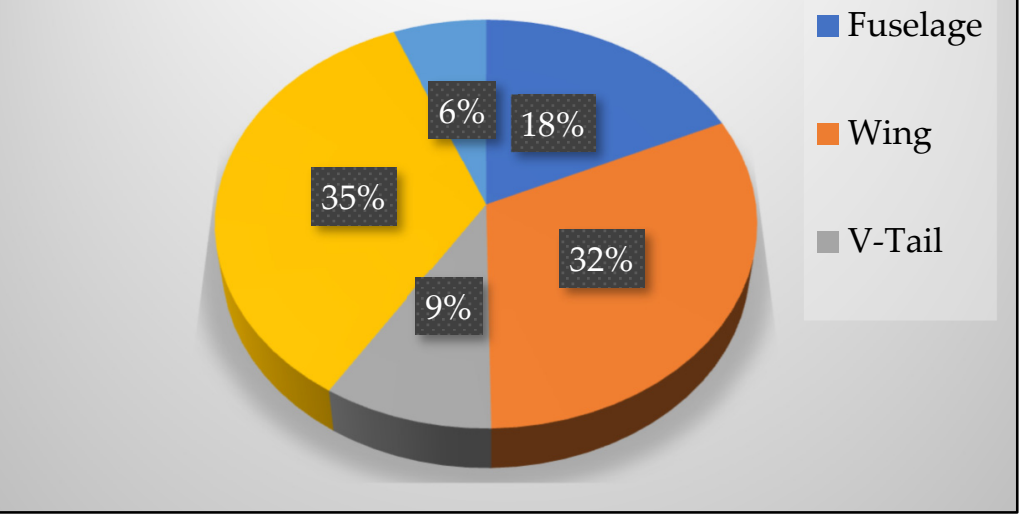

Figure 22. Pie chart of major contributors of parasite drag.

Table 14. Boundary conditions for drag calculations.

\begin{tabular}{cc}
\hline Mode & Cruise mode \\
Velocity & $70 \mathrm{~m} / \mathrm{s}$ \\
Projected area & $30.644 \mathrm{~m}^{2}$ \\
Reynold's number at sea level & $7.42 \times 10^{6}$ \\
Reynold's number at $2000 \mathrm{~m}$ & $6.33 \times 10^{6}$ \\
\hline
\end{tabular}

From Figure 23, the coefficient of drag was found to be 0.0489 at sea level and 0.0495 at $2000 \mathrm{~m}$ altitude. The lift-to-drag ratio is 9.81 at sea level and 9.68 at $2000 \mathrm{~m}$ altitude, as plotted in Figure 24.

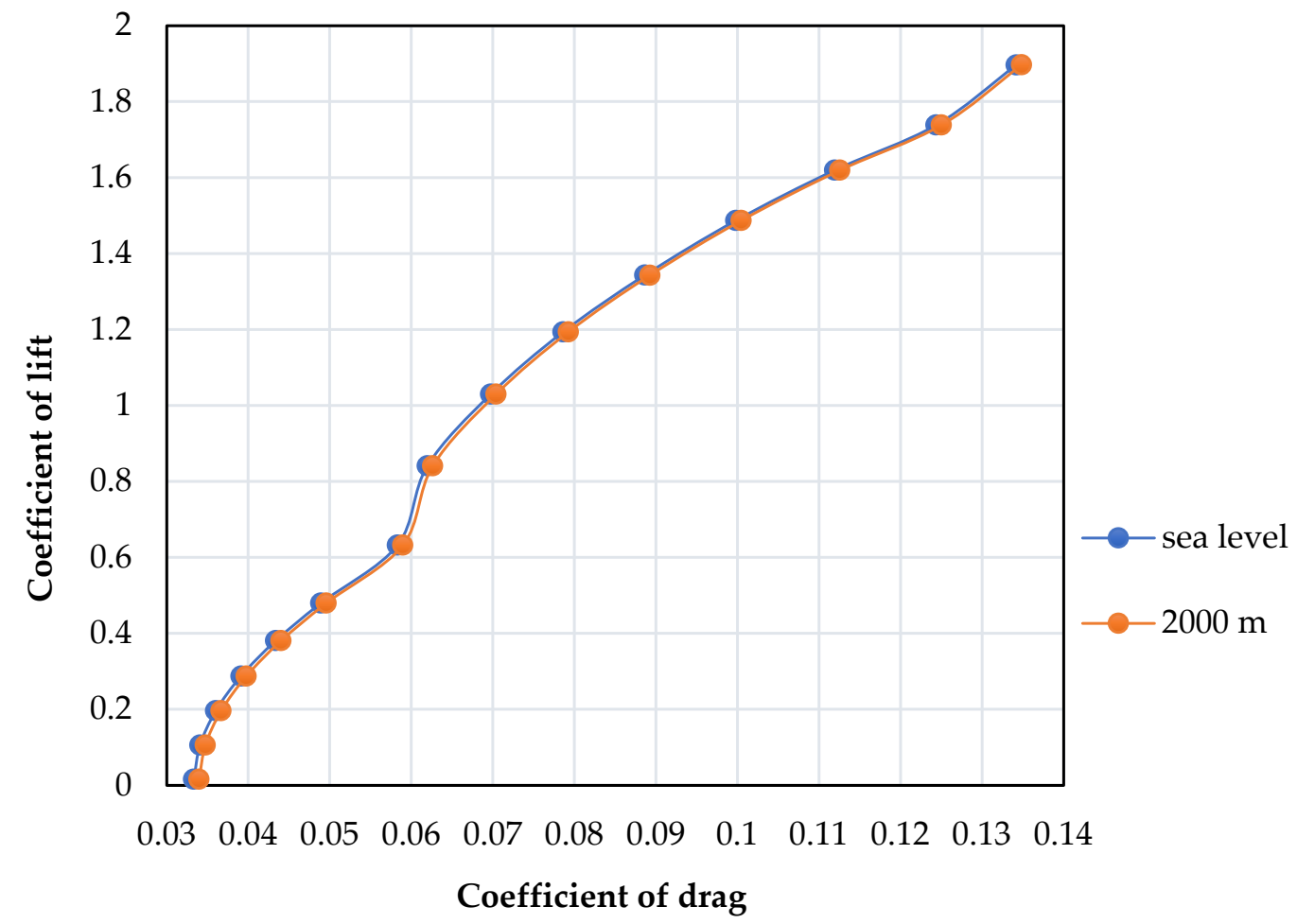

Figure 23. Coefficient of lift versus coefficient of drag. 


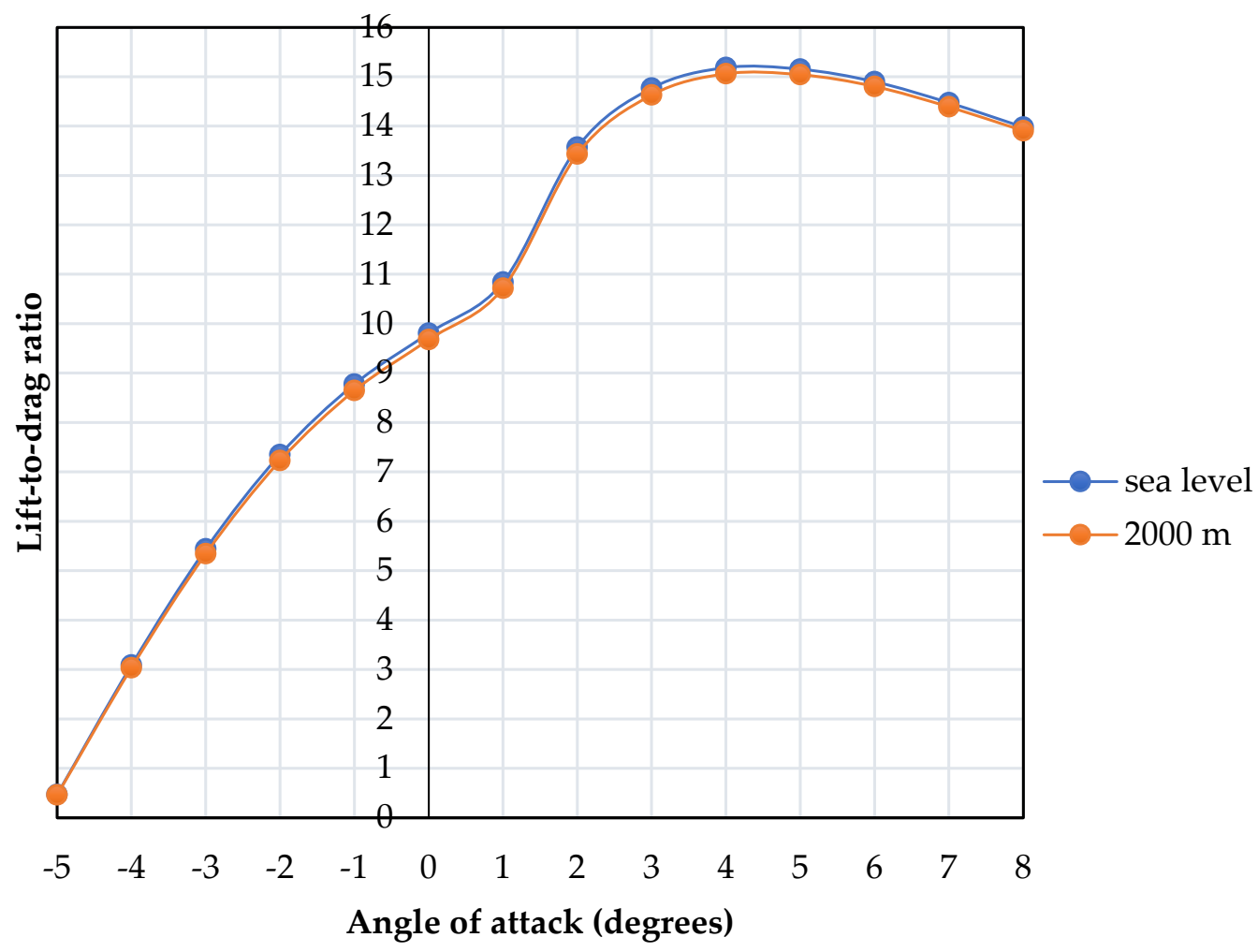

Figure 24. Lift-to-drag ratio versus angle of attack.

\subsection{Thrust Calculation}

The thrust force is the force that propels the aircraft forward. In this case, it also provides the power required for vertical take-off and landing. The thrust force is produced by open tilt-rotor-type propellers. There are six propellers in the present eVTOL model. A single propeller with a hub was designed in SolidWorks, as shown in Figure 25. The thrust produced by a single propeller was calculated in ANSYS Fluent under steady level flight conditions. The thrust was $222.86 \mathrm{~N}$ after applying the following boundary conditions in Table 15.

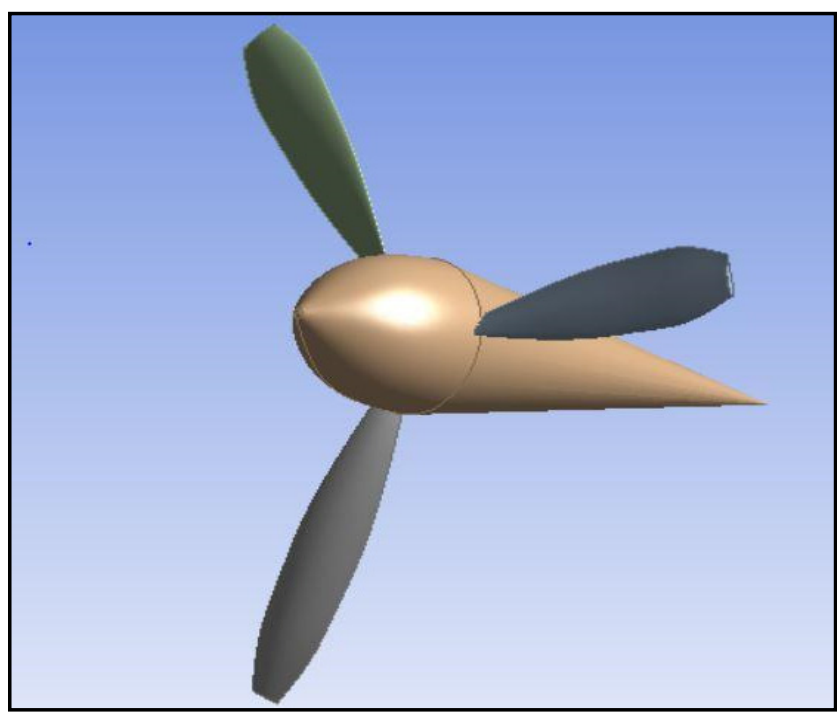

Figure 25. Propeller 3D model. 
Table 15. Boundary conditions for thrust calculations.

\begin{tabular}{cc}
\hline Total Area & $4.4643 \mathrm{~m}^{2}$ \\
Propeller Rpm & 6000 \\
Air Velocity & $70 \mathrm{~m} / \mathrm{s}$ \\
Pressure & $101,235 \mathrm{~Pa}$ \\
Density & $1.225 \mathrm{~kg} / \mathrm{m}^{3}$ \\
Altitude & Sea level conditions \\
Mesh Elements & 121,135 \\
Mesh Nodes & 22,016 \\
Viscous Model & K-epsilon \\
\hline
\end{tabular}

\subsection{Pressure Distributions}

Pressure distribution is the pressure at all points around the aircraft. Pressure distribution contours are used to determine the maximum pressure, average pressure and stagnation points on the eVTOL model. Figure 26 depicts the static pressure contours where the maximum value is $3.7 \mathrm{kPa}$ and the minimum value is $-4.7 \mathrm{kPa}$. The total pressure contours of the fuselage-wing model, shown in Figure 27, have maximum and minimum values of $3.98 \mathrm{kPa}$ and $-2.21 \mathrm{kPa}$, respectively.

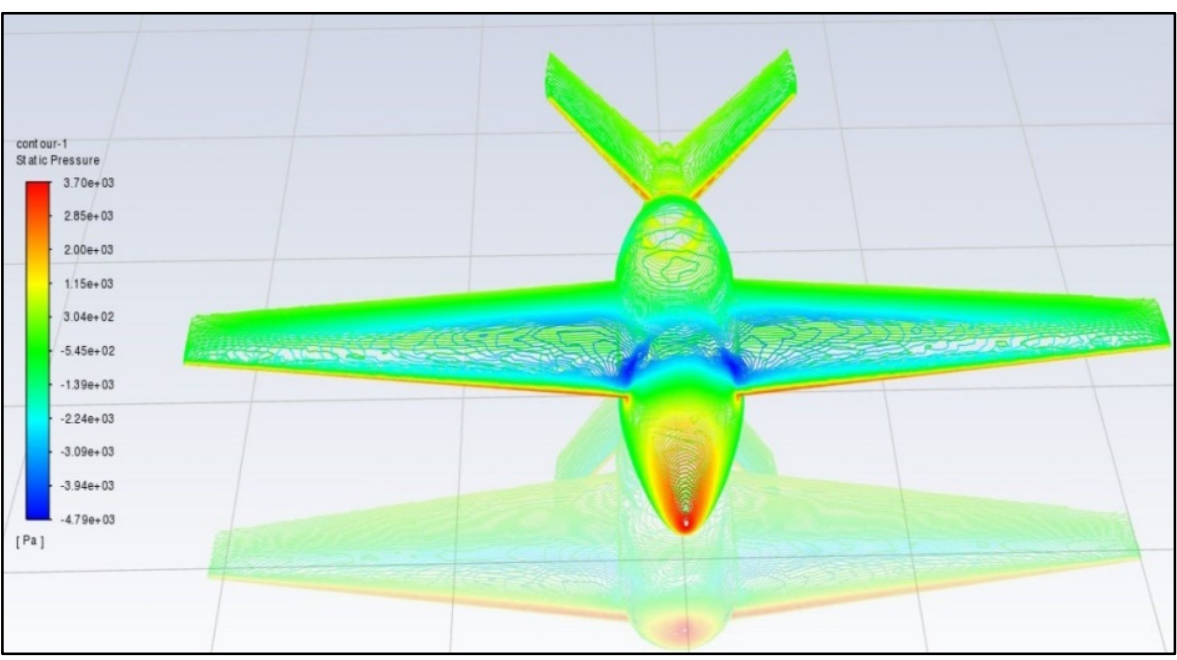

Figure 26. Static pressure contour.

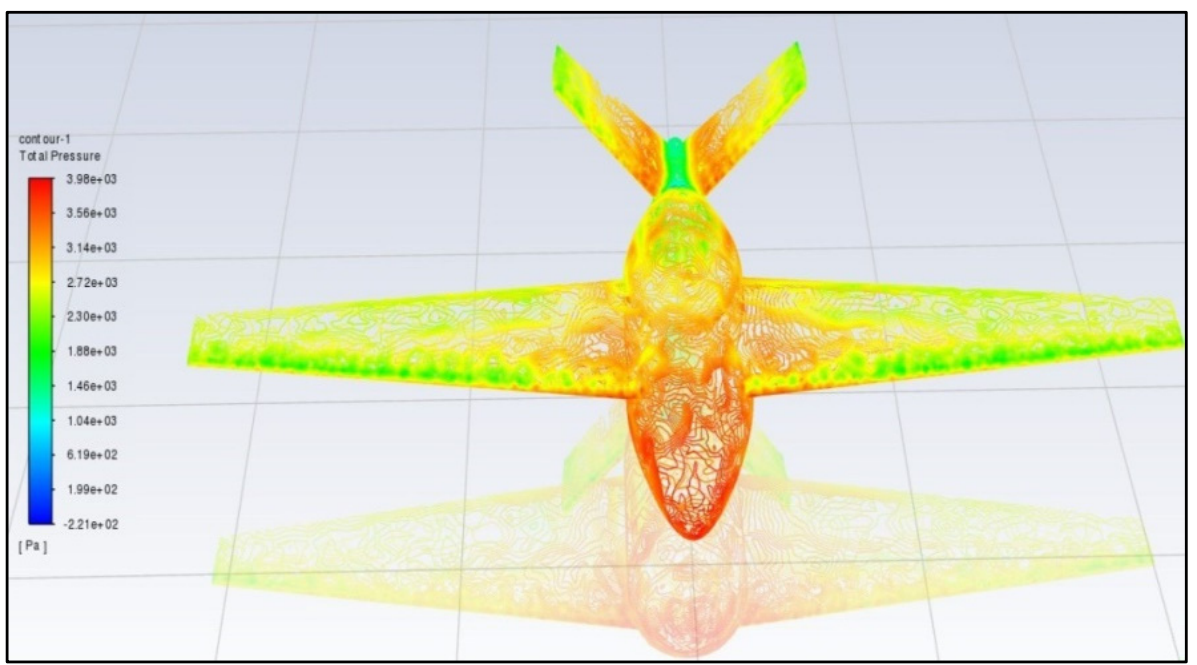

Figure 27. Total pressure contour. 
Figure 28 displays the static pressure contour at plane $\mathrm{XZ}$, where the maximum pressure occurs at the nose of the fuselage which confirms the stagnant conditions; the minimum pressure occurs at the streamlined top surface of the fuselage which confirms that the flow is attached and the velocity is maximum. The static pressure contour at plane $X Y$ in Figure 29 conveys the minimum pressure on the upper part of the wing which satisfies Bernoulli's equation.

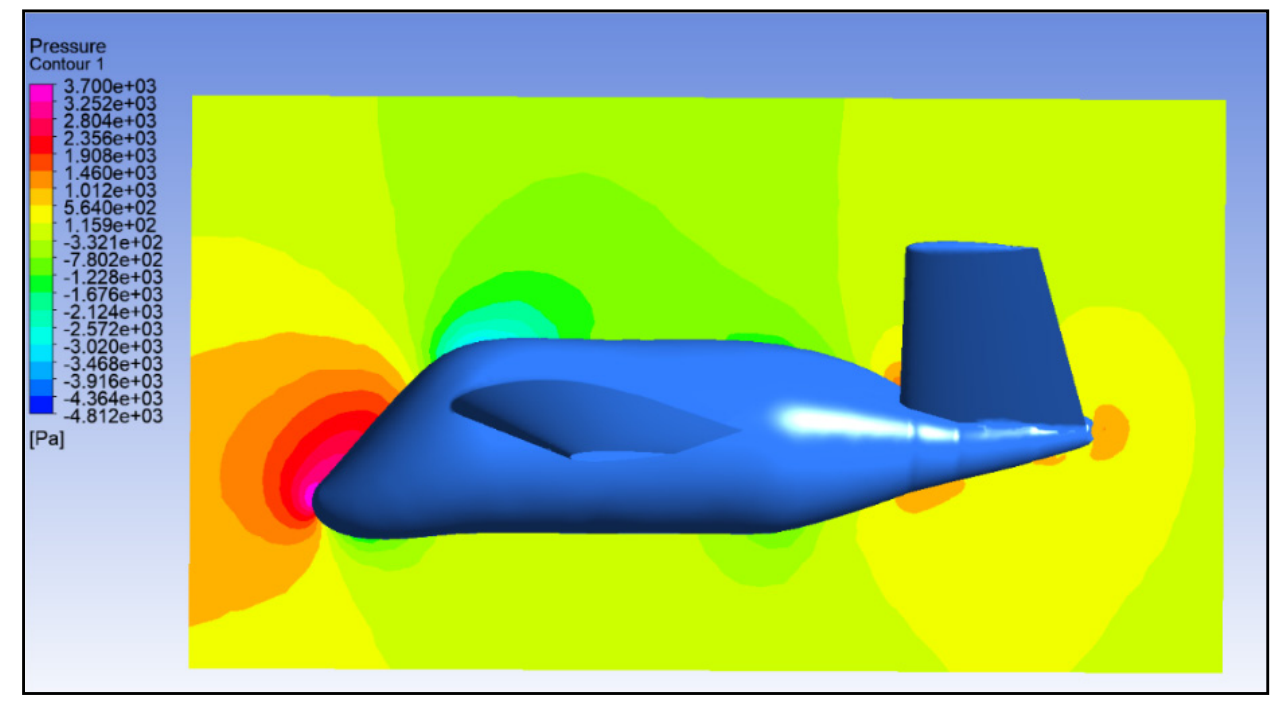

Figure 28. Static pressure contour at plane $X Z$.

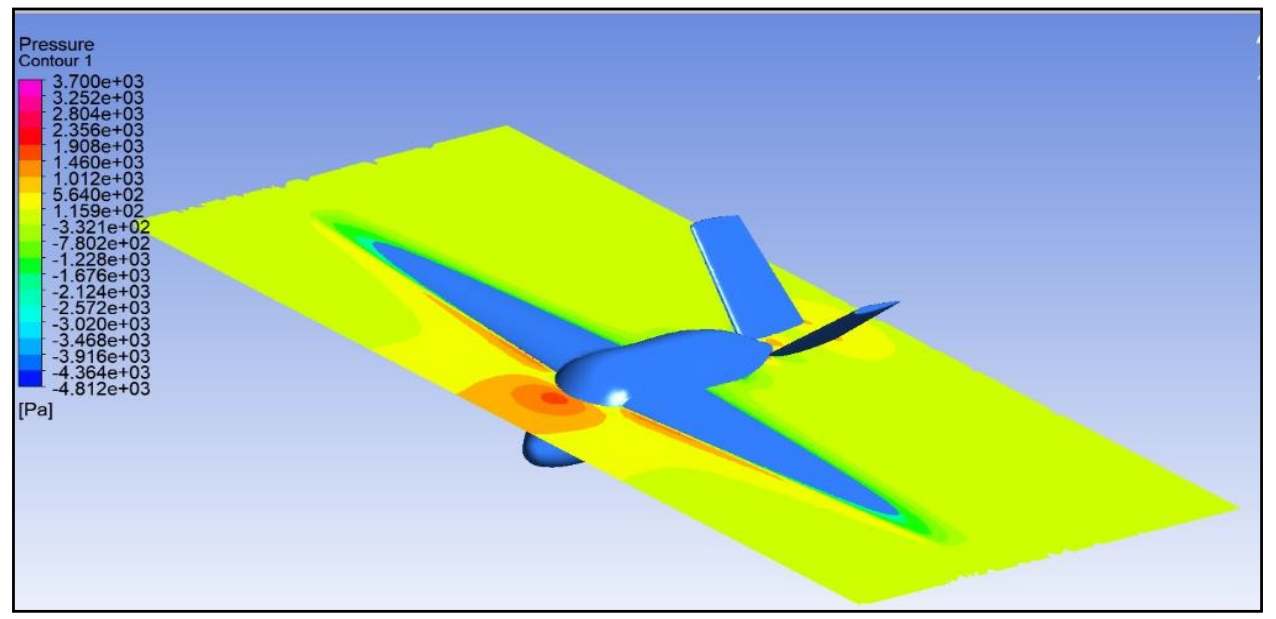

Figure 29. Static pressure contour at plane XY.

\subsection{Flow Interactions}

The art of making the flow pattern observable around the model is called flow visualization. In computational fluid dynamics (CFD), all of the fluid properties in space and time can be calculated from the mathematical solutions of the governing equations. The streamlines around the eVTOL model were visualized in the ANSYS Fluent Workbench. Figure 30 shows the velocity streamline profile at the $\mathrm{XY}$ plane where the maximum velocity $(111 \mathrm{~m} / \mathrm{s})$ occurs at the upper surface of the wing. The vorticity contour in Figure 31 shows the trailing vortices of the propellers of the aircraft which are modelled and analysed in OpenVSP. The maximum vorticity is $50 \mathrm{~m}^{2} / \mathrm{s}$ at the nose of the fuselage and the minimum vorticity is $-31.66 \mathrm{~m}^{2} / \mathrm{s}$ at the wing of the aircraft. The wingtip vortices get reduced by means of positioning the propeller by the tip of the wing. 


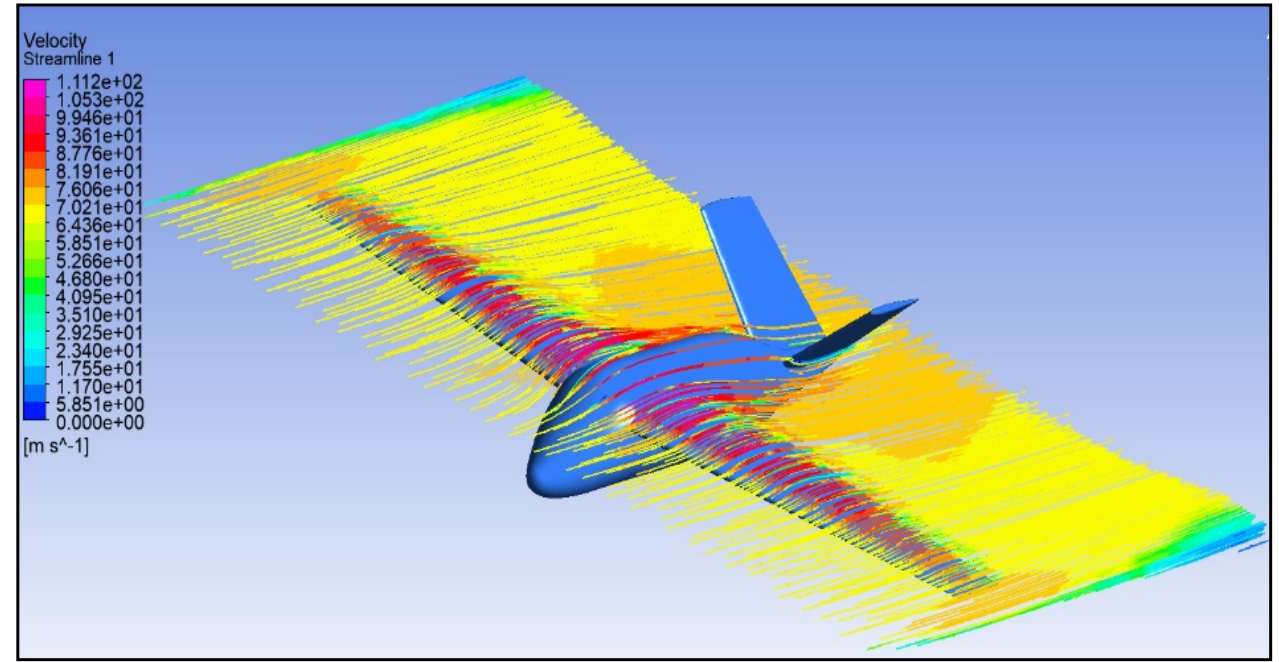

Figure 30. Velocity streamline at XY plane.

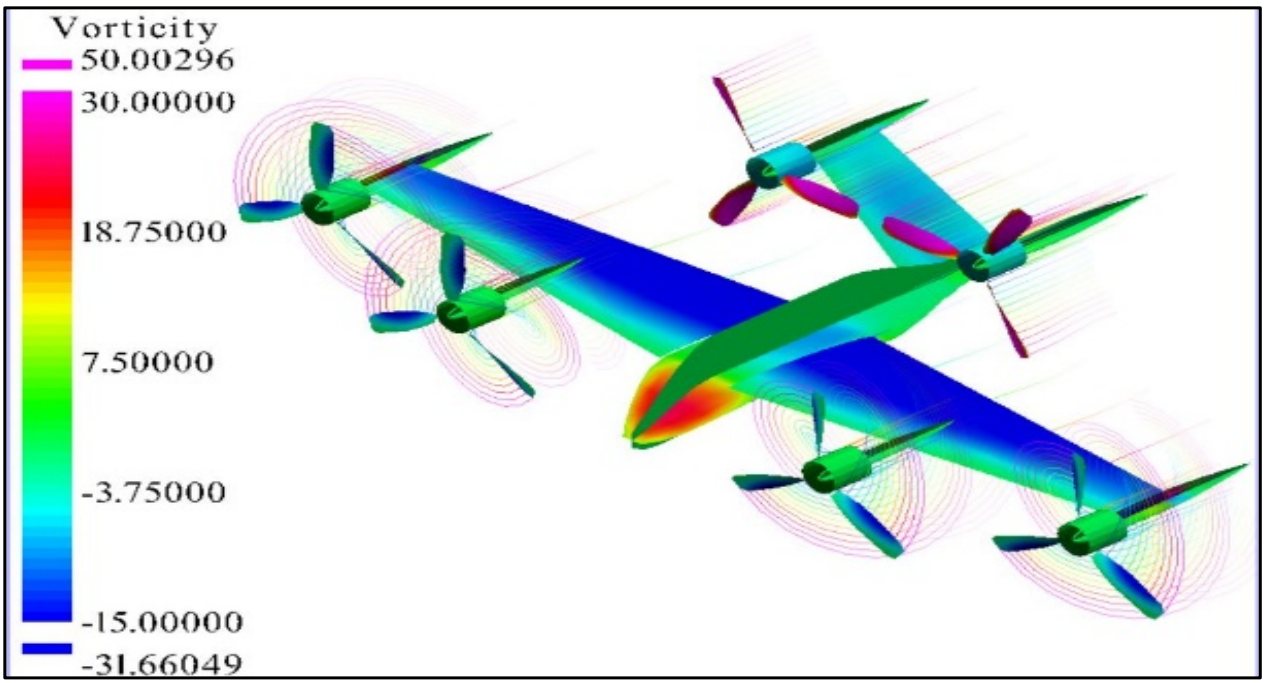

Figure 31 . Vorticity contour.

\section{Structural Analysis}

\subsection{Structural Analysis of Fuselage and Wing Structural Members}

The assemblies of the fuselage and wing components were examined by using ANSYS structural software. The SolidWorks model of the aircraft was imported to ANSYS for structural analysis by applying various loads over a fuselage. By considering the fuselagelike shell having $1 \mathrm{~mm}$-thick skin made up of carbon-fiber-reinforced polymer (CFRP) material, the analysis was performed for $100 \mathrm{kN}$ to understand the behaviour of the whole structure. The analysis output of the fuselage section and wing section were tabulated in Tables 16 and 17, respectively. Figure 32 represents the deformation contour of the fuselage when subjected to $100 \mathrm{kN}$ bending load and Figure 33 represents the deformation contour of the wing when subjected to $100 \mathrm{kN}$ bending load. Pertaining to the present aircraft weight $(17.216 \mathrm{kN})$, a $100 \mathrm{kN}$ load was used considering all of the major air loads during flight and in any adverse situations. Observations from Table 16 show that for a $100 \mathrm{kN}$ load, deformations were small in a range of centimetres. By increasing the thickness of the fuselage skin and considering the load on the aircraft, the deformations will be much smaller compared to the previously analysed case. The wing deformations tabulated in Table 17 were also small when subjected to $100 \mathrm{kN}$ load and will be in the range of 
millimetres when subjected to the actual load. This shows that the wing can bear the load and all of the other extra air loads during flight.

Table 16. Fuselage subjected to $100 \mathrm{kN}$.

\begin{tabular}{cccc}
\hline Serial Number & Load Type & Maximum Stress (GPa) & Maximum Deformation (m) \\
\hline 1. & Bending & 6.7 & 0.063 \\
2. & Shear & 0.307 & 0.011 \\
3. & Torsion & 6.587 & 0.227 \\
\hline
\end{tabular}

Table 17. Wing subjected to $100 \mathrm{kN}$.

\begin{tabular}{cccc}
\hline Serial Number & Load Type & Maximum Stress (GPa) & Maximum Deformation (m) \\
\hline 1. & Bending & 32.6 & 0.092 \\
2. & Shear & 0.198 & 0.001 \\
3. & Torsion & 35.8 & 0.015 \\
\hline
\end{tabular}

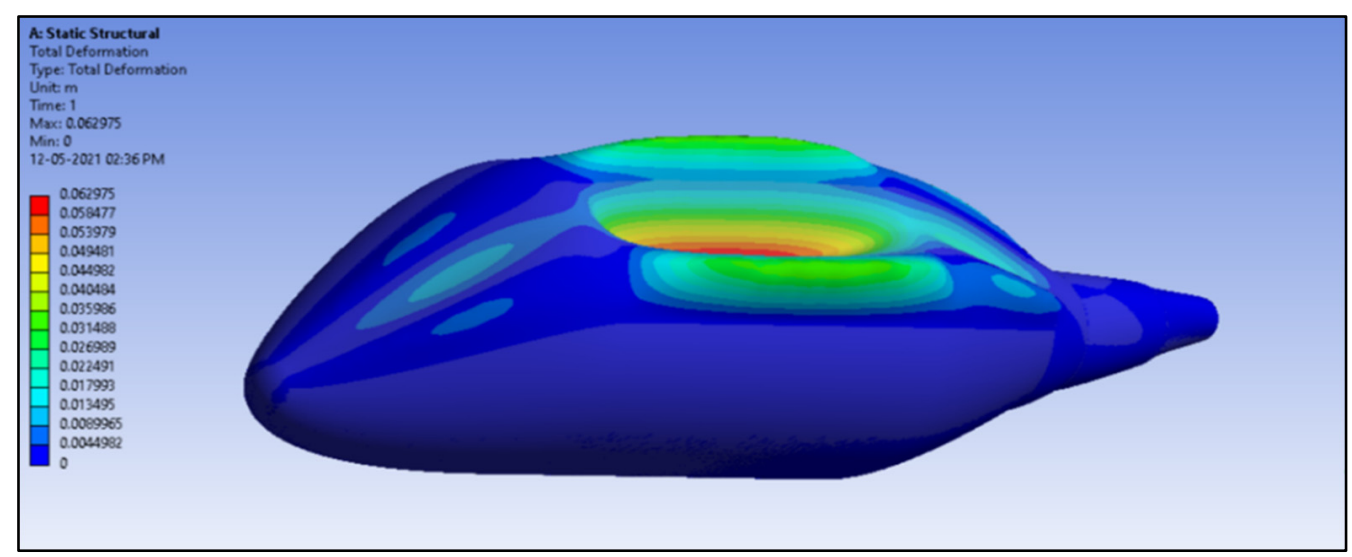

Figure 32. Deformation of fuselage subjected to $100 \mathrm{kN}$ bending load.

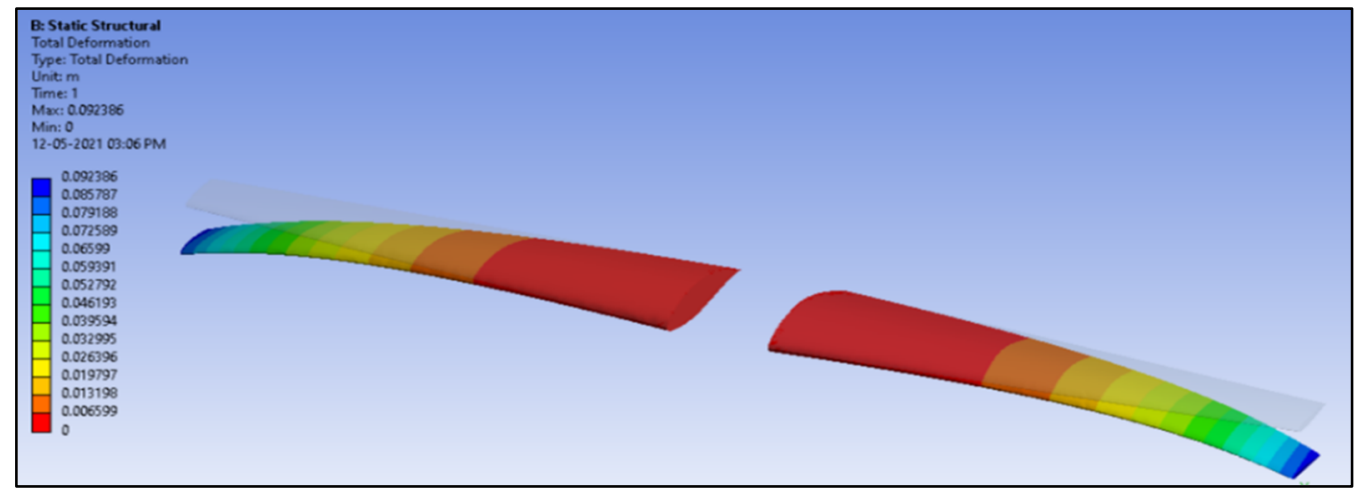

Figure 33. Deformation of wing subjected to $100 \mathrm{kN}$ bending load.

\subsection{Material Selection}

The skin of the fuselage, wing and ruddervator were examined first. The material selection for present eVTOL aircraft was directed by the following factors: low weight, high static strength, good fatigue performance and good fracture toughness.

CFRP was the material chosen for the skin of the wing, fuselage and ruddervator. CFRP is a light and strong composite material made up of carbon. This improves the performance of the fatigue resistance property. Even though the cost is much higher, the properties of the CFRP are much better compared relative to other composites [40]. 
Titanium (Ti 10-2-3) was preferred in the landing gear as an alternative to steel. The key purpose for this alteration was the weight reduction of $272 \mathrm{~kg}$ in the present design, as the strength-to-weight ratio of titanium is more than steel. The density is $4650 \mathrm{~kg} / \mathrm{m}^{3}$. The Ti 10-2-3 is a high-strength alloy and made up of titanium, aluminium, iron and vanadium. It has a tensile strength of $1170 \mathrm{MPa}$ and a yield strength of $1105 \mathrm{MPa}$. Landing gear has to be developed in a certain way, where the forces will not surpass the maximum strength of $1105 \mathrm{MPa}$ and it will not be damaged. Its melting point is $1649{ }^{\circ} \mathrm{C}$ and it has a high corrosion resistance [41].

It has a maximum factor of safety and high stress and deflection resistance. Therefore, the landing gear was considered safer using Titanium 10Al-2Fe-3V material and would evade structural failure. The Lamitex PL-68 has a high mark of resin impregnation and delivers good dimensional stability, high compressive, flexural and bond strength. It is mainly suggested for small air tools, motor vanes in air motors, starter motors, etc. This material was used for the motors in the present eVTOL aircraft [42]. Aircraft windows and pilot windshields are made of a form of plexiglass such as polycarbonate or acrylic plastics. This material is lightweight, transparent and relatively strong. The sound attenuating honeycomb enables engine designers to attain superior acoustical performance, dramatic noise and structural weight reduction during take-off and landing. It reduces the engine noise produced by motor fans by up to $30 \%$ [43].

\section{Aircraft Performance}

\subsection{Vertical Take-Off Performance}

i. $\quad$ Vertical take-off: The aircraft carries out a vertical take-off from 0 to 80 metres. It has no horizontal velocity. The vertical thrust is the outcome of the six engines of the aircraft pointed upwards. The thrust produced elevates the aircraft in the hover up phase. The vertical speed is $2 \mathrm{~m} / \mathrm{s}$.

ii. Climb: The eVTOL aircraft transits to a state where the wings also start to produce lift. This is conducted by controlling the RPM of the tail rotors to provide enough downforce of the tail to increase the angle of attack of the aircraft. From calculations, it was assumed that the wing will produce $75 \%$ of the lift required during the climb. The rest is produced by the propellers. It is also important to note that the propellers also overcome both the drag and weight during the climb. The climb phase takes place between the altitudes of $80 \mathrm{~m}$ to $2000 \mathrm{~m}$. The rate of climb of the aircraft is $2 \mathrm{~m} / \mathrm{s}$.

iii. Cruise: The eVTOL aircraft completely transits to a state where all lift required is produced by only the wing. The propellers produce the thrust required for forward flight. The cruise phase takes place at an altitude of $2000 \mathrm{~m}$ for a range of $496.56 \mathrm{~km}$. The mean horizontal speed was taken as the cruise speed, which is $69 \mathrm{~m} / \mathrm{s}$.

iv. Descent: The descent phase takes place from an altitude of $2000 \mathrm{~m}$ to $80 \mathrm{~m}$ at a descent rate of $2 \mathrm{~m} / \mathrm{s}$. The mean horizontal velocity is $21 \mathrm{~m} / \mathrm{s}$. This takes place for a horizontal distance of $1.72 \mathrm{~km}$.

v. Hover down: The hover down phase takes place from an altitude of 80 to $0 \mathrm{~m}$. The hover down speed is $2 \mathrm{~m} / \mathrm{s}$.

Table 18 summarizes the parameter values corresponding to each mission phase.

Table 18. Parameter values for each phase.

\begin{tabular}{cccccc}
\hline $\begin{array}{c}\text { Mission } \\
\text { Phase }\end{array}$ & Time (s) & $\begin{array}{c}\text { Mean Horizontal } \\
\text { Speed (m/s) }\end{array}$ & $\begin{array}{c}\text { Mean Vertical } \\
\text { Speed }(\mathbf{m} / \mathbf{s})\end{array}$ & $\begin{array}{c}\text { Energy } \\
(\mathbf{M J})\end{array}$ & L/D \\
\hline Hover Up & 40 & 0 & 2 & 15.68 & - \\
Climb & 80 & 21 & 2 & 70 & 12.3 \\
Cruise & 7142 & 69 & 0 & 740 & 13.3 \\
Descent & 80 & 21 & 2 & 70 & 12.3 \\
Hover Down & 40 & 0 & 2 & 15.68 & - \\
\hline
\end{tabular}




\subsection{V-n Diagram}

Upon drawing the V-n diagram for the present design, the following characteristics can be identified:

- $\quad$ Stall velocity, $35 \mathrm{~m} / \mathrm{s}$;

- Manoeuvring velocity, $68 \mathrm{~m} / \mathrm{s}$;

- Negative manoeuvring velocity, $55 \mathrm{~m} / \mathrm{s}$;

- $\quad$ Cruise velocity, $69 \mathrm{~m} / \mathrm{s}$;

- Maximum load factor $n,+3.8$;

- Maximum negative load factor $n,-1.52$.

The load factors are as imposed by regulation 14, CFR 23, issued by the Federal Aviation Administration. Figure 34 shows the V-n diagram for the present eVTOL aircraft.

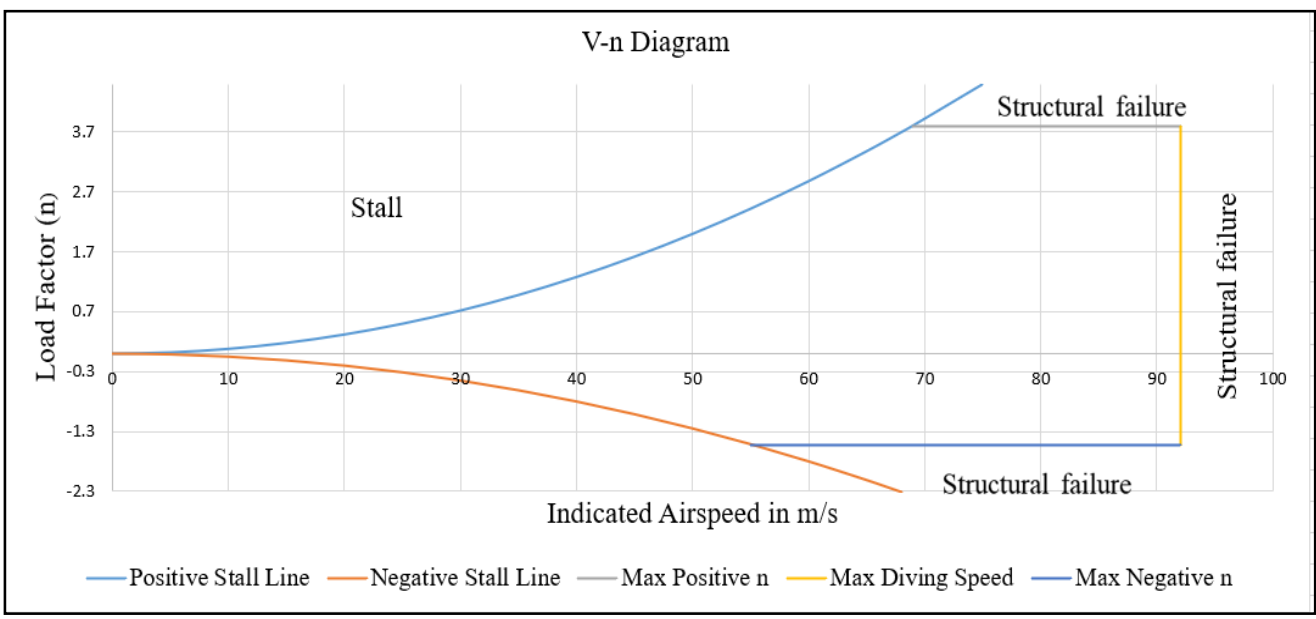

Figure 34. V-n diagram for the present aircraft.

\section{Aircraft Stability and Control}

\subsection{Longitudinal Static Stability}

For the aircraft to possess longitudinal static stability, it has to be able to hold the changes in the angle of attack by creating an opposing pitching moment. In other terms, a derivative of the pitching moment coefficient with respect to the angle of attack must be negative $\left(\mathrm{Cm}_{\alpha}<0\right)$. Various stability derivatives linked to lift and moments were estimated using the methods outlined in Raymer [28] and Anderson [44] and mentioned in Table 19. The moment coefficient at zero angle of attack is positive $\left(\mathrm{Cm}_{0}>0\right)$ and the trim angle of attack $\left(\alpha_{e}\right)$ is well within the flight range, as shown in Figure 35. These two conditions indicate that the present eVTOL aircraft is both longitudinally stable and balanced.

Table 19. Longitudinal stability derivatives.

\begin{tabular}{ccccc}
\hline Derivatives (Unit-Per Radian) & $\mathbf{C}_{\mathbf{L} \boldsymbol{\alpha}}$ & $\mathbf{C m}_{\boldsymbol{\alpha}}$ & $\mathbf{C m}_{\boldsymbol{\delta} \mathbf{e}}$ & $\mathbf{C m}_{\mathbf{0}}$ \\
\hline Values & 8.77 & -0.718 & -3.09 & 0.114 \\
\hline
\end{tabular}

$\mathrm{C}_{\mathrm{L} \alpha}$ is the lift curve slope of the wing. The negative value of $\mathrm{Cm}_{\alpha}$, as shown in Table 19, shows that the present design has longitudinal static stability. An increase in the angle of attack resulted inactively in the creation of a restoring pitching moment. Moreover, the negative value of the derivative of the pitching moment coefficient with respect to the ruddervator angle $\left(\mathrm{Cm}_{\delta \mathrm{e}}\right)$, proposed that a positive ruddervator deflection further led to a counterbalancing pitch moment. The neutral point and static margin were found from the equations provided in the research of Raymer [28] and mentioned in Table 20. The lengths were measured from the nose of the aircraft, whereas the static margin was specified as a percentage of the mean aerodynamic chord. This positive static margin specified that 
the centre of gravity was way ahead of the neutral point, showing that this aircraft was longitudinal statically stable.

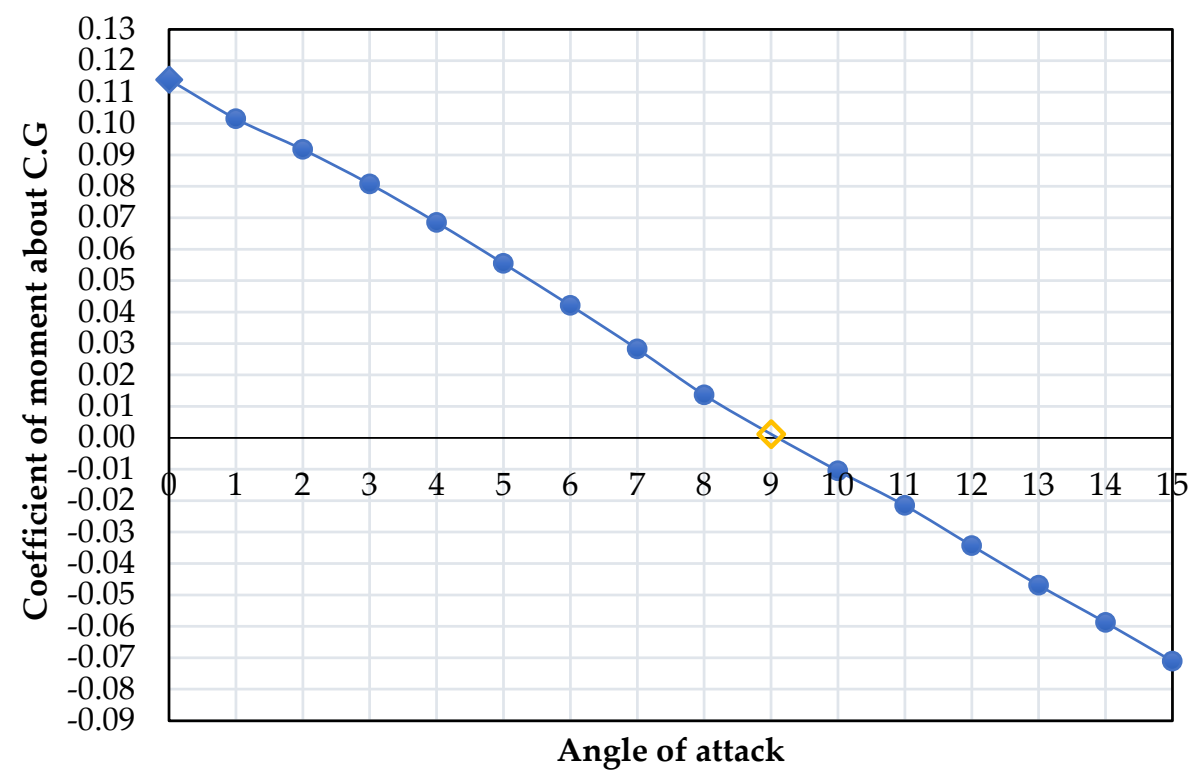

Figure 35. Coefficient of moment versus angle of attack.

Table 20. Neutral point and static margin.

\begin{tabular}{ccccc}
\hline Parameter & Neutral Point & Static Margin & CG (Empty) & CG (Fully Loaded) \\
\hline Values & $2.7 \mathrm{~m}$ & $29.4-41.2 \%$ & $2.0 \mathrm{~m}$ & $2.2 \mathrm{~m}$ \\
\hline
\end{tabular}

\subsection{Lateral-Directional Static Stability}

To thoroughly understand the stability of the aircraft, the lateral-directional static stability was also analysed. Using the method given in the research of McCormick [32], several stability derivatives used to govern the lateral-directional stability were estimated. The negative value of the derivative $\mathrm{Cl}_{\beta}$ shows that the aircraft certainly produced a restoring roll moment, when a change in the sideslip angle is given. The positive value of derivative $\mathrm{Cn}_{\beta}$ specified that a counteracting yaw moment happened in the case of a sideslip change. $\mathrm{Cl}_{\mathrm{r}}$ and $\mathrm{Cn}_{\mathrm{r}}$ are derivative of rolling moment coefficient and derivative of yawing moment coefficient with respect to roll rate, respectively. These derivatives were calculated from the method outlined in Raymer [28] and were tabulated in Table 21, thus proving that the present design has lateral-directional static stability.

Table 21. Lateral-directional stability derivatives.

\begin{tabular}{ccccc}
\hline Derivatives (Per Radian) & $\mathbf{C l}_{\boldsymbol{\beta}}$ & $\mathbf{C n}_{\boldsymbol{\beta}}$ & $\mathbf{C l}_{\mathbf{r}}$ & $\mathbf{C n}_{\mathbf{r}}$ \\
\hline Values & -0.495 & 1.153 & 0.12 & -0.063 \\
\hline
\end{tabular}

\subsection{Dynamic Stability}

Dynamic characteristics were also examined along with the static ones. The six degrees of freedom equations of motion, as given in McCormick [32], were solved for their roots, from which dynamic modes were estimated, along with other characteristics.

Table 22 shows the calculated longitudinal dynamic stability values. It is observed from the calculated values that the present aircraft has excellent longitudinal dynamic stability.

Where $\omega_{n}$ is natural frequency, $\zeta$ is damping ratio, $T_{P}$ is time period and $T_{1 / 2}$ is time to damp to half-amplitude. 
Table 22. Longitudinal dynamic stability.

\begin{tabular}{cccccc}
\hline Dynamic Mode & Roots & $\boldsymbol{\omega}_{\mathbf{n}}$ & $\zeta$ & $\mathbf{T}_{\mathbf{P}}$ & $\mathbf{T}_{\mathbf{1 / 2}}$ \\
\hline Phugoid & $-0.015765+0.21582 \mathrm{i}$ & $0.217 \mathrm{~Hz}$ & 0.0728 & $29.1 \mathrm{~s}$ & $43.94 \mathrm{~s}$ \\
Short period & $-2.28323+3.6704 \mathrm{i}$ & $4.32 \mathrm{~Hz}$ & 0.528 & $1.71 \mathrm{~s}$ & $0.3 \mathrm{~s}$ \\
\hline
\end{tabular}

\subsection{Dynamic Simulations}

Longitudinal dynamic stability was also simulated in MATLAB Simulink (Aerospace Toolbox and Aerospace Blockset) software. The considered aerodynamic model block (Figure 36) consists of aerodynamic forces of the aircraft. The coefficient of drag versus angle of attack, coefficient of lift versus angle of attack and coefficient of moment versus angle of attack graphs were given as inputs. Environmental parameters were given according to the design cruise altitude $(2000 \mathrm{~m})$. The three DOF equations of motion (EOM) model (Figure 36) converted the weight, aerodynamic forces and moments to the aircraft's position, acceleration and rotation on both axis at each time step. Finally, the results were visualized using the scope block.

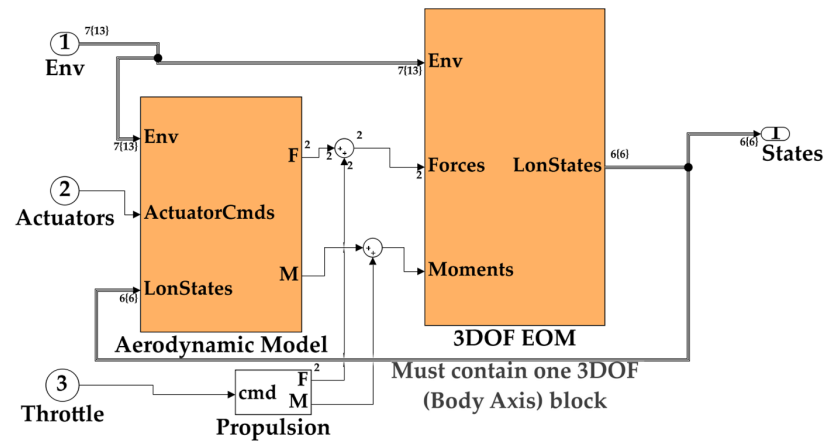

Figure 36. Block diagram used for longitudinal dynamic stability.

Pitch angle $(\theta)$ versus time (Figure 37), altitude (h) versus time (Figure 38) and angle of attack versus time (Figure 39) graphs were obtained from simulations. Figures 37 and 38 refer to the phugoid mode only, since the angle of attack is constant in phugoid mode. Figure 39 refers to short period mode. Figures 37-39 show that the amplitude dampens over a period of time. The amplitude dampens quickly which shows that the aircraft has good longitudinal dynamic stability.

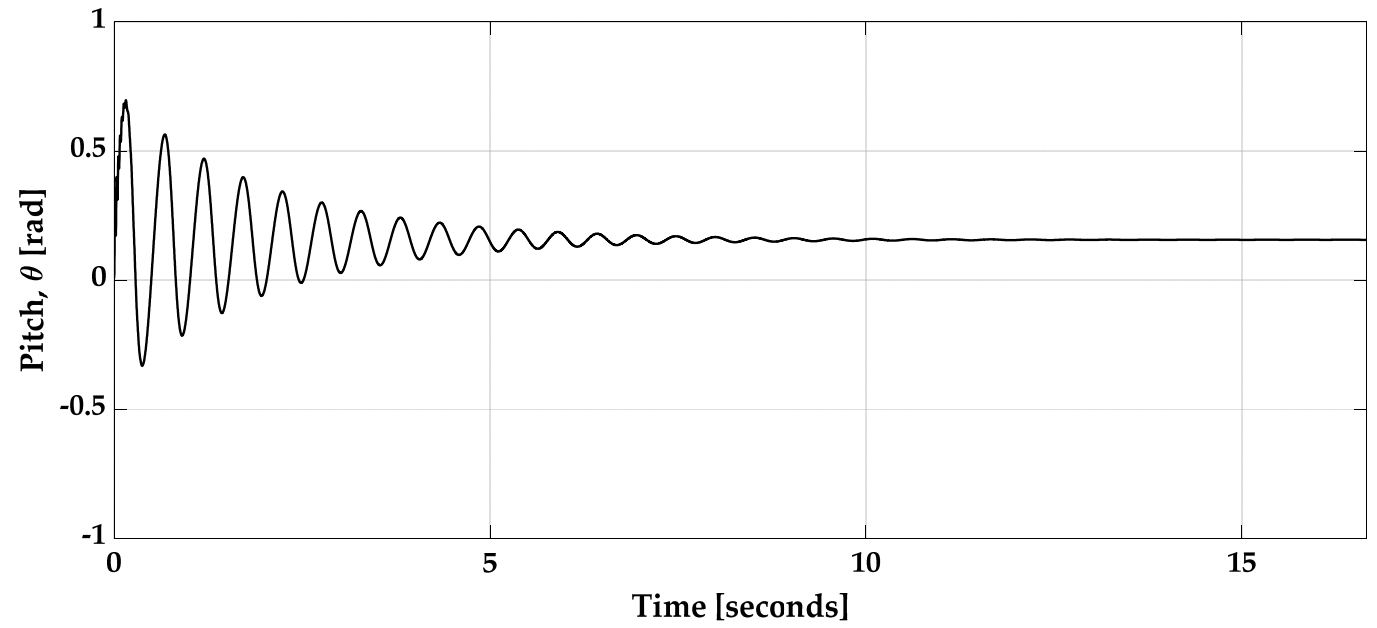

Figure 37. Pitch angle $(\theta)$ versus time plot for longitudinal stability case. 


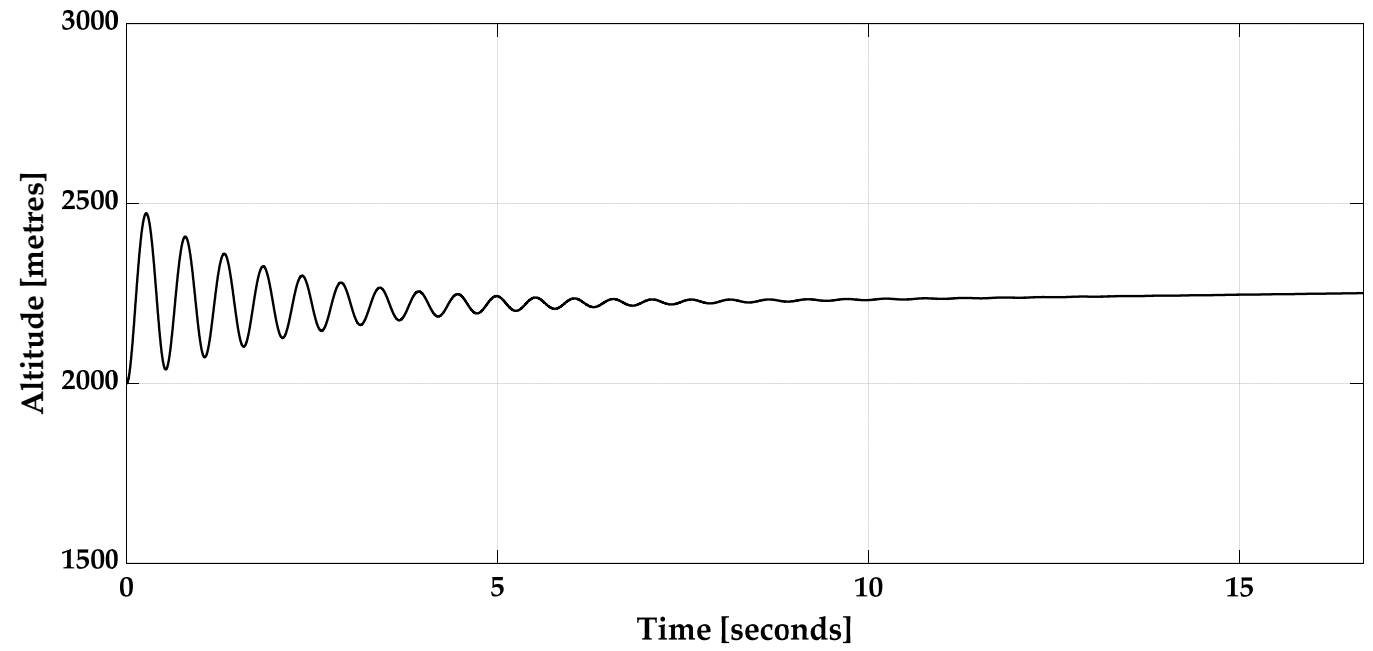

Figure 38. Altitude (h) versus time plot for longitudinal stability case.

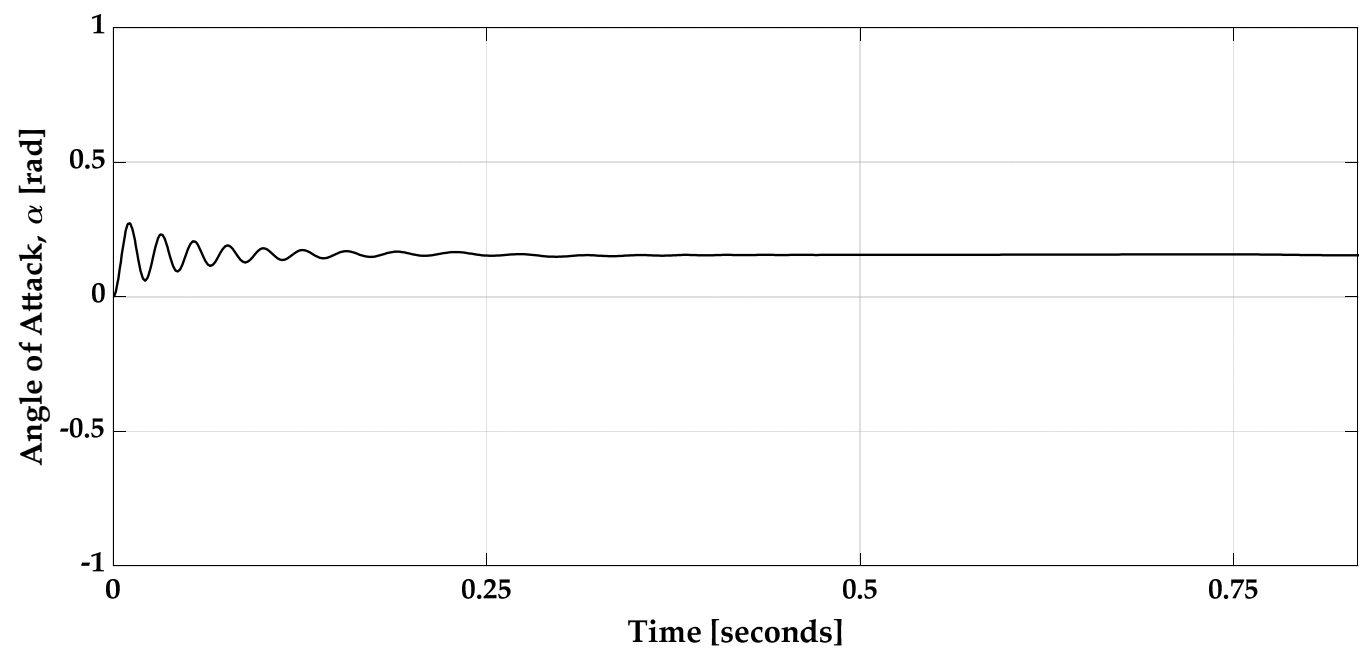

Figure 39. Angle of attack $(\alpha)$ versus time plot for longitudinal stability case.

\section{Cost Estimation and Technological Forecast}

\subsection{Cost Estimation}

The various methods of cost estimation are cost-estimating relationship, defence contractors planning report, aeronautical manufacturers planning report, modular life cycle cost model, and the RAND DAPCA IV model. Here, the RAND DAPCA IV model has been modified slightly to obtain the cost estimation of the eVTOL aircraft.

\subsubsection{Cost Estimation Using Modified RAND DAPCA IV Model}

Equations (26)-(33) were used for cost estimation using the modified RAND DAPCA IV model [28,45];

$$
\begin{gathered}
\text { Engineering hours }\left(\mathrm{H}_{\mathrm{E}}\right)=5.18 \mathrm{~W}_{\mathrm{e}}^{0.777} \mathrm{~V}^{0.894} \mathrm{Q}^{0.163} \\
\text { Tooling hours }\left(\mathrm{H}_{\mathrm{T}}\right)=7.22 \mathrm{~W}_{\mathrm{e}}^{0.777} \mathrm{~V}^{0.696} \mathrm{Q}^{0.263} \\
\text { Manufacturing hours }\left(\mathrm{H}_{\mathrm{M}}\right)=10.5 \mathrm{~W}_{\mathrm{e}}^{0.777} \mathrm{~V}^{0.484} \mathrm{Q}^{0.641} \\
\text { QC hours }\left(\mathrm{H}_{\mathrm{Q}}\right)=0.133\left(\mathrm{H}_{\mathrm{M}}\right) \\
\text { Development support cost }\left(\mathrm{C}_{\mathrm{D}}\right)=67.4 \mathrm{~W}_{\mathrm{e}}^{0.63} \mathrm{~V}^{1.3} \\
\text { Flight test cost }\left(\mathrm{C}_{\mathrm{F}}\right)=1947 \mathrm{~W}_{\mathrm{e}}^{0.325} \mathrm{~V}^{0.822} \mathrm{FTA}^{1.21}
\end{gathered}
$$




$$
\text { Manufacturing materials cost }\left(\mathrm{C}_{\mathrm{M}}\right)=31.2 \mathrm{~W}_{\mathrm{e}}^{0.921} \mathrm{~V}^{0.621} \mathrm{Q}^{0.799}
$$

Propulsion cost: estimated USD 19,685.21

RDT\&E + Flyaway $=\left(H_{E} R_{E}\right)+\left(H_{T} R_{T}\right)+\left(H_{M} R_{M}\right)+\left(H_{Q} R_{Q}\right)+C_{D}+C_{F}+C_{M}+$ Propulsion cost + Avionics cost

where RDT\&E is Research, Development, Test and Evaluation, $\mathrm{W}_{\mathrm{e}}$ is empty weight, $\mathrm{Q}$ is lesser of production quantity or number to be produced in five years, $\mathrm{V}$ is maximum velocity, FTA is the number of flight-test aircraft, $R_{E}, R_{T}, R_{M}$ and $R_{Q}$ are average wrap rates of engineering, tooling, manufacturing and quality control. Thus, using the average costing method, the eVTOL aircraft for the prescribed design shall cost between the range of USD $14.83 \mathrm{M}$ to USD $17.36 \mathrm{M}$.

\subsubsection{Cost Comparison with Existing eVTOL}

In comparison with all the existing eVTOL models, the present aircraft model shows a lesser value of price gradient in the number of planes manufactured versus the cost plot. As an example, the Rolls Royce air taxi manufactures an eVTOL at an estimated cost of around USD $1 \mathrm{bn}$, which is around four times that of the present estimated value. Thus, the present model has the maximum efficiency of all of the eVTOLs of similar cost.

\subsection{Technological Forecast in Battery and Cargo Systems}

A thorough understanding on the technological growth in the aviation sector is required for selecting batteries. Many studies have been conducted and articles have been written tracking the developments over decades and predicting future growth. As far as the storage systems are considered, there have been many conceptual developments, such as a removable fuselage to get passengers down safely in the event of an accident. An article from 2018 explains it clearly [46]. It is usually stated in almost any sector that 'going green' is the next big step. This is due to huge amounts of emissions during operations. An article titled 'The Future of Aircraft propulsion' [47] states that 3.2 tons of $\mathrm{CO}_{2}$ is emitted upon burning one ton of jet fuel and about 3.6 tons of $\mathrm{CO}_{2}$ is emitted upon burning one ton of avgas. This clearly shows why using electric or at least hybrid power is very important. The usage of green propulsion is very important. Some of the specifications for an ideal battery include a low weight/volume ratio, high specific energy, high specific power, affordability, rechargeability, longevity, minimal toxicity and fast charging.

A detailed discussion on "intelligent engines", which will run automatically to keep the pressure ratios across the compressor, the fuel-to-air ratio, the atomization and mixing of the fuel to the optimum to get maximum efficiency, is presented in [48]. It also provides a review of multi-electric engines. Various historical milestones have been achieved so far and electric propulsion is a potential application in commercial aviation [49]. A report by the International Air Transport Association (IATA) [50] clearly shows that electric air taxis with two passengers will be ready by 2025. As seen in various R \& D projects around the globe, we can comfortably state that we have reached that stage and are now moving to increase the efficiency of this technology.

Different types of electric batteries have been developed in the last decade to increase the output, decrease toxicity and reduce charging time. It can be seen that most of the auto industry uses NMC (nickel-manganese-cobalt) batteries and major developments are being made for other batteries as well. Tesla currently uses NCA (nickel-cobalt-aluminium oxide) batteries in its electric cars [51]. However, cobalt is still toxic and lithium-sulphur batteries are better in terms of toxicity. It can be comfortably considered that by 2030, lithium-sulphur batteries will be available for use [52], which has been taken in this conceptual design.

\section{Relevance of Present Design and Analysis}

Using the iteration methodology, various parameters of the design were calculated and iterated to the best value. The present design is a tilt-rotor which performs better than 
a tilt-wing, as a tilt-wing has very high-power requirements during transition from hover to cruise due to its wings acting as air brakes. The wing of the final design is a tapered wing. A taper ratio of 0.35 was used to decrease the wingtip vortices while maintaining the structural strength of the wing. A mechanical twist of -2 degrees was given to avoid tip stall. The fuselage was an aerodynamic fuselage with a rear upsweep of 15 degrees to ensure easy cargo loading. A V-tail was used, decreasing the wetted area which decreases the drag. It also provided a clearance from the front downwash.

Weights of different components (Table 3), the dimensions of the control surfaces (Table 10), different types of drags (Section 9) and the centre of gravity (Section 8) of the aircraft were calculated. Apart from theoretical calculations, the model was designed in SolidWorks and analysed in various softwares viz. OpenVSP, ANSYS. Various pressure and streamline contours (Figures 26-30), vorticity contour (Figure 31) and deformation contours (Figures 32 and 33) were plotted. The deformations were well within the allowed limit confirming the integrity of the design. Further calculations proved that the present aircraft design has good longitudinal static and dynamic stability as well as lateral-directional static stability. MATLAB simulations showed that the aircraft possessed exceptional longitudinal dynamic stability. The six large rotors facilitated low disk loading and thereby improved the hover efficiency over other designs with several small rotors. The design has a wellbalanced, symmetric placement of motors to ensure uniform and efficient lift during take-off and enough thrust during cruise. The RAND DAPCA method was employed to estimate the price of the present design.

The novelty in the design can be evidently observed. As compared to the existing models, the present design has an aerodynamic fuselage with an upsweep. This unique design helps in clear visibility which is highly beneficial during urban transportation, i.e., near-rooftop flights, while also having ease of cargo usage. The empennage section is designed in a way to decrease the stresses on the rear of the fuselage and give clearance to the ruddervators and rear propellers from the wing downwash. New implementations such as stall-proof characteristics, lighter fast-charging batteries are a few of the other features demonstrating the innovations brought to the design. Understanding the importance of the environment, the present design employs a fully electric solution. The whole composite airframe structure cuts weight and deducts the manufacturing cost for a bigger rate of production. This is one of the major unique selling points of the design and will benefit the production company immensely.

\section{Conclusions}

This paper presented the conceptual design of an electric VTOL aircraft for urban air mobility. In the coming decades, the expanse of intercity eVTOL aircraft flying over large cities is predicted to grow really fast. The objective was to establish a well-designed aircraft, satisfying all of the intercity travel mission requirements. The final result of this work is a five-seater intercity electric VTOL air taxi, which can even be shifted to cargo mode. This work would certainly be a baseline guide to researchers and manufacturers working in this field. The present eVTOL aircraft design comprises an aerodynamically shaped fuselage, a tapered wing and a V-tail. The six tilt-rotor propeller engines help the aircraft to take up to $500 \mathrm{~kg}$ of payload and fly up to a maximum range of $500 \mathrm{~km}$ at a cruise speed of $200 \mathrm{~km} / \mathrm{h}$, with a self-weight of $1255 \mathrm{~kg}$. The unit price is expected to be range between USD 14.83 and USD 17.36 million. Theoretically, and according to the analysis, the present design is aerodynamically efficient, cost efficient and structurally and dynamically stable, making it one of the best models of eVTOL. The next step of the present aircraft's conceptual design is the preliminary and detailed design phase.

Author Contributions: Conceptualization, original draft preparation, S.A., A.A., B.P., V.S.J.R., R.S. and V.M.S.; software, formal analysis, A.A., B.P. and V.S.J.R.; writing-review and editing, supervision, V.M.S. All authors have read and agreed to the published version of the manuscript.

Funding: This research received no external funding. 
Data Availability Statement: All results are presented in article and other than this, no new data were created or analysed in this study. Data sharing is not applicable to this article.

Acknowledgments: The initial work was carried out as part of the 4th National Aircraft Conceptual Design Competition (NACDeC-IV) held during 2020-21 under the aegis of The Aeronautical Society of India Design Division and Mumbai Branch. The authors would like to thank the organizing committee of NACDeC-IV for conducting various webinars and doubt-clarification sessions as part of this event.

Conflicts of Interest: The authors declare no conflict of interest.

\section{References}

1. Kraenzler, M.; Schmitt, M.; Stumpf, E. Conceptual Design Study on Electrical Vertical Take Off and Landing Aircraft for Urban Air Mobility. In Proceedings of the AIAA Aviation Forum 2019, Dallas, TX, USA, 17-21 June 2019; ISBN 978-1-62410-589-0. [CrossRef]

2. Xiao, J.; Salk, N.; Haran, K. Conceptual Design of an eVTOL Air Shuttle for Rapid Intercity Transport. In Proceedings of the IEEE Power and Energy Conference at Illinois (PECI), Champaign, IL USA, 27-28 February 2020; pp. 1-8; ISBN 978-1-72815-299-8. [CrossRef]

3. Taarabt, S.A.; Bernier, A.T.; Chen, Y.; Compere, H.; Dore, A.; Fransolet, M.; Jumpertz, R.D.; Macchiaiolo, L. Graduate Team Aircraft Design Competition: Electric Vertical Takeoff and Landing (E-VTOL) Aircraft Mistral Air Taxi Team Name: The Huggy's Birds. 2019. Available online: https:/ /www.aiaa.org/docs/default-source/uploadedfiles/education-and-careers/universitystudents / design-competitions/3rd-place-grad-team-aircraft.pdf (accessed on 7 January 2021).

4. Udroiu, R.; Blaj, M.-I. Conceptual design of a VTOL remotely piloted aircraft for emergency missions. Sci. Res. Educ. Air Force 2016, 18, 207-214. [CrossRef]

5. Bacchini, A.; Cestino, E. Electric VTOL Configurations Comparison. Aerospace 2019, 6, 26. [CrossRef]

6. Crawford, C.C.; Heiges, M.W.; Wasikowski, M. Analysis of Tiltwing Aircraft Configuration Potential. SAE Trans. 1996, 105, 1267-1280. [CrossRef]

7. Datta, A. Commercial Intra-City on Demand of Electric-VTOL Status of Technology. Technical Report. 2018. Available online: https:/ / vtol.org/files/dmfile/tvf.wg2.yr2017draft.pdf (accessed on 14 January 2021).

8. Kundu, A.K.; Price, M.A.; Riordan, D. Conceptual Aircraft Design: An Industrial Approach; Wiley: Hoboken, NJ, USA, 2019; p. 1056; ISBN 978-1-119-50028-5.

9. Farokhi, S. Future Propulsion Systems and Energy Sources in Sustainable Aviation; Aerospace Series; John Wiley \& Son, Inc.: Hoboken, NJ, USA, 2019; p. 445; ISBN 978-1-119-41505-3.

10. Kuhn, I.F., Jr. Purebred and Hybrid Electric VTOL Tilt Rotor Aircraft. U.S. Patent No. 8,469,306, 25 June 2013. Available online: https:/ / patentimages.storage.googleapis.com/8f/30/10/f7104b6f2b3a76/WO2010123601A1.pdf (accessed on 21 January 2021).

11. Pham, R.N. High Performance VTOL Convertiplanes. U.S. Patent No. 6,974,105, 13 December 2005. Available online: https: / / portal.unifiedpatents.com/patents/patent/US-6974105-B2 (accessed on 28 January 2021).

12. Jain, A.; Bavikar, K.; Sanjay, A.; Gupta, M.; Gupta, B.R.; Dineshkumar, H. Baseline procedure for conceptual designing of an eVTOL for Urban Air Mobility. In Proceedings of the 2020 4th International Conference on Electronics, Communication and Aerospace Technology (ICECA), Tamil Nadu, India, 5-7 November 2020; pp. 1173-1178. [CrossRef]

13. Bacchini, A.; Cestino, E. Key Aspects of Electric Vertical Take-off and Landing Conceptual Design. Proc. Inst. Mech. Eng. Part G J. Aerosp. Eng. 2020, 234, 774-787. [CrossRef]

14. Palaia, G.; Abu Salem, K.; Cipolla, V.; Binante, V.; Zanetti, D. A Conceptual Design Methodology for e-VTOL Aircraft for Urban Air Mobility. Appl. Sci. 2021, 11, 10815. [CrossRef]

15. Bacchini, A.; Cestino, E.; Van Magill, B.; Verstraete, D. Impact of lift propeller drag on the performance of eVTOL lift+cruise aircraft. Aerosp. Sci. Technol. 2021, 109, 106429. [CrossRef]

16. eVTOL Aircraft Directory, Electric VTOL News by the Vertical Flight Society. Available online: https://evtol.news/aircraft (accessed on 6 February 2021).

17. OpenVSP. Open Source Parametric Aircraft Geometry Tool. Available online: http:/ / openvsp.org/ (accessed on 13 February 2021).

18. Bartini Flying Car. Available online: https: / / evtol.news/bartini/ (accessed on 20 February 2021).

19. Bartini Flying Car. Official Website. Available online: https://bartini.aero/ (accessed on 27 February 2021).

20. Types of Landing Gear. Available online: https://www.flight-mechanic.com/landing-gear-types-landing-gear-arrangement/ (accessed on 5 March 2021).

21. Ailerons. Available online: https://www.skybrary.aero/index.php/Ailerons (accessed on 12 March 2021).

22. V-Tail. Available online: http://youshouldfly.com/Rhyolite_Aviation/V-Tail_info.html (accessed on 19 March 2021).

23. NACA 0010. Available online: http://airfoiltools.com/airfoil/details?airfoil=naca0010-il (accessed on 26 March 2021).

24. Sanchez-Carmona, A.; Cuerno-Rejado, C. Vee-tail conceptual design criteria for commercial transport aeroplanes. Chin. J. Aeronaut. 2019, 32, 595-610. [CrossRef]

25. Tilt Rotors. Available online: https://en.wikipedia.org/wiki/Tiltrotor (accessed on 4 April 2021). 
26. Will Graf, E. Effects of Duct Lip Shaping and Various Control Devices on the Hover and Forward Flight Performance of Ducted Fan UAVs. Ph.D. Dissertation, Virginia Polytechnic Institute and State University, Blacksburg, VI, USA, 2005. Available online: http:/ / www.dept.aoe.vt.edu/ \{\}mason/Mason_f/WillGrafMSThesis.pdf (accessed on 11 April 2021).

27. FAA Report on Transport Heliports. Available online: https://www.faa.gov/documentLibrary/media/advisory_circular/1505390-2B/150_5390_2b_part2.pdf (accessed on 18 April 2021).

28. Raymer, D.P. Aircraft Design: A Conceptual Approach, 6th ed.; AIAA Education Series; Virginia Polytechnic Institute and State University: Blacksburg, VI, USA, 2018; ISBN 978-1-62410-490-9.

29. Hascaryo, R.W.; Merret, J.M. Configuration-Independent Initial Sizing Method for UAM/eVTOL Vehicles. In Proceedings of the AIAA AVIATION Forum, Online. 15-19 June 2020; p. 16; ISBN 978-1-62410-598-2. [CrossRef]

30. NACA 643618. Available online: http:/ / airfoiltools.com/airfoil/details?airfoil=naca643618-ilu (accessed on 25 April 2021).

31. Abbott, I.H.; Von Doenhoff, A.E. Theory of Wing Sections: Including a Summary of Airfoil Data, 1st ed.; Dover Publications: Mineola, NY, USA, 1959; p. 693; ISBN 9780486605869.

32. McCormick, B.W. Aerodynamics, Aeronautics and Flight Mechanics, 2nd ed.; John Wiley \& Sons, Inc.: New York, NY, USA, 1994; p. 664; ISBN 978-0-471-57506-1.

33. Roskam, J. Airplane Design Part 3; Roskam Aviation and Engineering Corporation: Ottawa, KS, Canada, 1987; ISBN 978-1-884885-09-9.

34. Composites in Aircrafts. Available online: https://www.compositesworld.com/articles/flying-high-on-composite-wings (accessed on 3 May 2021).

35. Cinar, G.; Cai, Y.; Chakraborty, I.; Mavris, D.N. Sizing and Optimization of Novel General Aviation Vehicles and Propulsion System Architectures. In Proceedings of the 2018 Aviation Technology, Integration, and Operations Conference, Atlanta, GA, USA, 25-29 June 2018; ISBN 978-1-62410-556-2. [CrossRef]

36. Brushless Motor. Available online: https:/ / www.freerchobby.cc/products/mp154120-40kw-brushless-motor-with-85kg-thrustfor-big-drone-plane (accessed on 10 May 2021).

37. Master Airscrew. Available online: https://www.masterairscrew.com/products/3-blade-16x10-propeller (accessed on 17 May 2021).

38. Jeevanantham, V.; Vadivelu, P.; Manigandan, P. Material Based Structural Analysis of a Typical Landing Gear. IJISET 2017, 4, 2348-7968. Available online: http://ijiset.com/vol4/v4s4/IJISET_V4_I04_34.pdf (accessed on 24 May 2021).

39. Aircraft Tire-Engineering Data. Available online: https://www.jupitor.co.jp/pdf/michelin_aircraft.pdf (accessed on 31 May 2021)

40. Bachmann, J.; Yi, X.; Gong, H.; Martinez, X.; Bugeda, G.; Oller, S.; Tserpes, K.; Ramon, E.; Paris, C.; Moreira, P.; et al. Outlook on ecologically improved composites for aviation interior and secondary structures. CEAS Aeronaut. J. 2018, 9, 533-543. [CrossRef]

41. Myagkov, L.L.; Mahkamov, K.; Chainov, N.D.; Makhkamova, I. Advanced and conventional internal combustion engine materials. In Alternative Fuels and Advanced Vehicle Technologies for Improved Environmental Performance; Elsevier: Amsterdam, The Netherlands, 2014; pp. 370-408; ISBN 978-0-85709-522-0.

42. Lamitex PL-68. Available online: http://www.naplastics.com/pump-vanes-blades (accessed on 2 June 2021).

43. Sound Attenuating Honeycomb. Available online: https://www.hexcel.com/Products/Honeycomb/HexWeb-Acousti-Cap (accessed on 9 June 2021).

44. Anderson, J.D. Introduction to Flight, 3rd ed.; McGraw-Hill Series in Aeronautical and Aerospace Engineering; McGraw-Hill: New York, NY, USA, 1989; p. 616; ISBN 978-0-07-100496-1.

45. Jenkinson, L.R.; Marchman, J.F. Aircraft Design Projects: For Engineering Students; Butterworth-Heinemann: Amsterdam, The Netherlands, 2003; ISBN 978-0-7506-5772-3.

46. Detachable Fuselage Aircraft. Available online: https://www.treehugger.com/plane-detachable-fuselage-could-really-take-4855 350 (accessed on 16 June 2021).

47. Future of Aircraft Propulsion. Available online: https://aero-space.eu/2021/01/04/the-future-of-aircraft-propulsion/ (accessed on 23 June 2021).

48. Yi, Y. Review and Future of Aircraft's Propulsion Type. J. Phys. Conf. Ser. 2019, 1345, 032075. [CrossRef]

49. Gohardani, A.S.; Doulgeris, G.; Singh, R. Challenges of future aircraft propulsion: A review of distributed propulsion technology and its potential application for the all electric commercial aircraft. Prog. Aerosp. Sci. 2011, 47, 369-391. [CrossRef]

50. Technology Roadmap to 2050. Available online: https://www.iata.org/contentassets/8d19e716636a47c184e7221c77563c93/ technology20roadmap20to20205020no20foreword.pdf (accessed on 30 June 2021).

51. Tesla Batteries. Available online: https://www.cnbc.com/2020/06/30/tesla-and-the-science-of-low-cost-next-gen-ev-millionmile-battery.html (accessed on 1 July 2021).

52. Technology Watch. Aerospace Technology Institute (ATI). Available online: https://www.ati.org.uk/wp-content/uploads/2021 /09/ati-insight-03-emerging-technologies-in-commercial-aircraft-systems.pdf (accessed on 8 July 2021). 